Supporting Information

\title{
Characterization of Ligand Adsorption at Individual Gold Nanocubes
}

Myung-Hoon Choi, Soojin Jeong, Yi Wang, Sang-Joon Cho, ${ }^{1}$ Sang-il Park, ${ }^{1}$ Xingchen Ye*, and Lane A. Baker*

Department of Chemistry

Indiana University

800 E. Kirkwood Avenue

Bloomington, Indiana 47405

${ }^{1}$ Park Systems Corporation

KANC 4F

Gwanggyo-ro 109

Suwon 16229

Korea

* To whom correspondence should be addressed.

(LAB) E-mail: lanbaker@indiana.edu; Phone: +1-812-856-1873

(XY) Email: xingye@indiana.edu; Phone: +1-812-855-3500

KEYWORDS: cetyltrimethylammonium bromide, gold nanoparticles, atomic force microscopy, force-distance spectroscopy, electrochemical cleaning, correlative measurement

Number of pages: 36

Number of figures: 23

Number of tables: 8 


\section{Contents}

1. Synthesis and Characterization of Au NCs

2. FT-IR Spectroscopy Measurements to Optimize Methanol Washing

3. In Situ AFM Operation

4. Scanning Electron Microscopy Measurements of Au NCs

5. In Situ AFM Measurements of Au NCs

6. Sidewall Artifacts Analysis of In Situ AFM Topographies

7. Correlative SEM and In Situ AFM Measurements and Data Analysis

8. In Situ AFM measurements of GC Substrates

9. Reference 


\section{Synthesis and Characterization of Au NCs}

\section{Reagents}

Hydrogen tetrachloroaurate trihydrate $\left(\mathrm{HAuCl}_{4} \cdot 3 \mathrm{H}_{2} \mathrm{O}, \geq 99.9 \%\right.$ trace metals basis), sodium borohydride $\left(\mathrm{NaBH}_{4}, 99 \%\right)$, silver nitrate $\left(\mathrm{AgNO}_{3}, \geq 99.0 \%\right)$, L-ascorbic acid $(\geq 99.5 \%)$, hydrochloric acid $(\mathrm{HCl}, 37 \%)$ and nitric acid $\left(\mathrm{HNO}_{3}, 70 \%\right)$ were purchased from Sigma Aldrich. Hexadecyltrimethylammonium bromide $(\mathrm{CTAB},>98.0 \%)$ and hexadecylpyridinium chloride monohydrate $(\mathrm{CPC},>98.0 \%)$ were purchased from TCI America. Potassium bromide $(\mathrm{KBr}$, $99.999 \%$ ) was purchased from Acros Organics. All chemicals were used as received without further purification. Ultrapure water (resistivity $=18.2 \mathrm{M} \Omega \cdot \mathrm{cm}$ at $25^{\circ} \mathrm{C}$ ) obtained from a Barnstead $^{\circledR}$

GenPure $^{\circledR}$ (Thermo Scientific) water purification system was used in all experiments. All glassware was cleaned with aqua regia (a mixture of $\mathrm{HCl}$ and $\mathrm{HNO}_{3}$ in $3: 1$ volume ratio), rinsed thoroughly with water and dried before use.

\section{Synthesis of Spherical Au Seeds}

Au nanospheres (NSs) were synthesized by modifying an iterative oxidative dissolution and reductive growth of Au nanorods (NRs) developed by the Mirkin group. ${ }^{1}$ Firstly, Au NRs were prepared by using a seed-mediated growth method. ${ }^{2} 125 \mu \mathrm{L}$ of $10 \mathrm{mM} \mathrm{HAuCl}_{4}$ solution was injected to $5 \mathrm{~mL}$ of $100 \mathrm{mM}$ CTAB solution. Then, freshly prepared $300 \mu \mathrm{L}$ of $\mathrm{NaBH}_{4}$ solution $(10 \mathrm{mM})$ was quickly introduced to the mixture under vigorous stirring. The seed solution was aged for 1 hour at room temperature (RT). Afterwards, $240 \mu \mathrm{L}$ of aged seed solution was added into the growth solution, which was the mixture of $10 \mathrm{~mL}$ of $10 \mathrm{mM} \mathrm{HAuCl}_{4}, 1.8 \mathrm{~mL}$ of $10 \mathrm{mM}$ $\mathrm{AgNO}_{3}$ and $1.2 \mathrm{~mL}$ of $100 \mathrm{mM}$ L-ascorbic acid, and $200 \mathrm{~mL}$ of $100 \mathrm{mM}$ CTAB solution. The 
reaction mixture was stirred for another $30 \mathrm{~s}$ followed by keeping at $30^{\circ} \mathrm{C}$ for 5 hours without stirring. Finally, the products were collected via centrifugation at $8000 \mathrm{rpm}$ for $10 \mathrm{~min}$, then redispersed in $50 \mathrm{mM}$ CTAB solution in optical density (O.D.) of 2.0 at the longitudinal plasmon peak wavelength.

For the synthesis of Au NSs, Au NRs were etched by adding $10 \mathrm{mM} \mathrm{HAuCl}_{4}$ into as-synthesized NR solution $(\mathrm{O} . \mathrm{D} .=2)$ to reach a final concentration of $75 \mu \mathrm{M}$ for $\mathrm{Au}^{3+}$, then kept for 3 hours at $40{ }^{\circ} \mathrm{C}$ with stirring. The products were retrieved by centrifugation at $8000 \mathrm{rpm}$ for $10 \mathrm{~min}$ followed by re-dispersion with $100 \mathrm{mM} \mathrm{CPC}$ to attain O.D.=1.0. Afterwards, Au concave rhombic dodecahedra (CRDs) were synthesized by using these etched NRs as seeds. Typically, $3 \mathrm{~mL}$ of etched NR solution was introduced to the mixture of $10 \mathrm{~mL}$ of $10 \mathrm{mM} \mathrm{CPC}, 175 \mu \mathrm{L}$ of $10 \mathrm{mM}$ $\mathrm{HAuCl}_{4}$, and $2.25 \mathrm{~mL}$ of $100 \mathrm{mM} \mathrm{L}$-ascorbic acid, then stirred for 15 minutes. The CRDs were recovered by centrifugation at $8000 \mathrm{rpm}$ for $10 \mathrm{~min}$ followed by dispersion with certain volume of $50 \mathrm{mM}$ CTAB solution to reach O.D. $=1$. Subsequent etching of these CRDs were induced by adding $10 \mathrm{mM} \mathrm{HAuCl}_{4}$ until a final concentration of $60 \mu \mathrm{M}$ is reached for $\mathrm{Au}^{3+}$. The reaction solution was kept at $40{ }^{\circ} \mathrm{C}$ for $4-6$ hours under stirring and the nanospheres were isolated by centrifugation at $8000 \mathrm{rpm}$ for 10 minutes. The size of final spherical seed particles was controlled by monitoring the extent of etching via UV-vis extinction spectroscopy at 30-minute intervals. For example, the reaction was stopped after 4.5 hours once the plasmonic absorption peak reached $524.0 \mathrm{~nm}$. The resultant nanospheres with an average diameter of ca. $19 \mathrm{~nm}$ were used as seeds for the preparation of Au nanocubes used in this work 


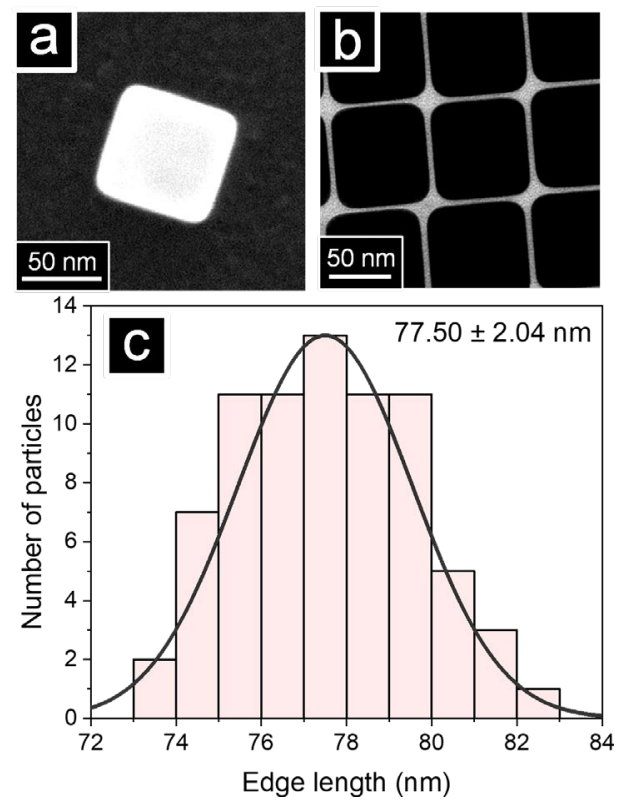

Figure S1. Representative electron micrographs of synthesized Au NCs measured by (a) SEM (ET detector) after CTAB ligand removal by methanol treatment and electrochemical cleaning and (b) TEM after centrifugation washing. (c) Histogram of the Au NC edge length. The black curve in (c) represents Gaussian fit to the corresponding distribution histogram. The average edge length of $\mathrm{Au} \mathrm{NC}$ is $77.5 \pm 2.04 \mathrm{~nm}$. 

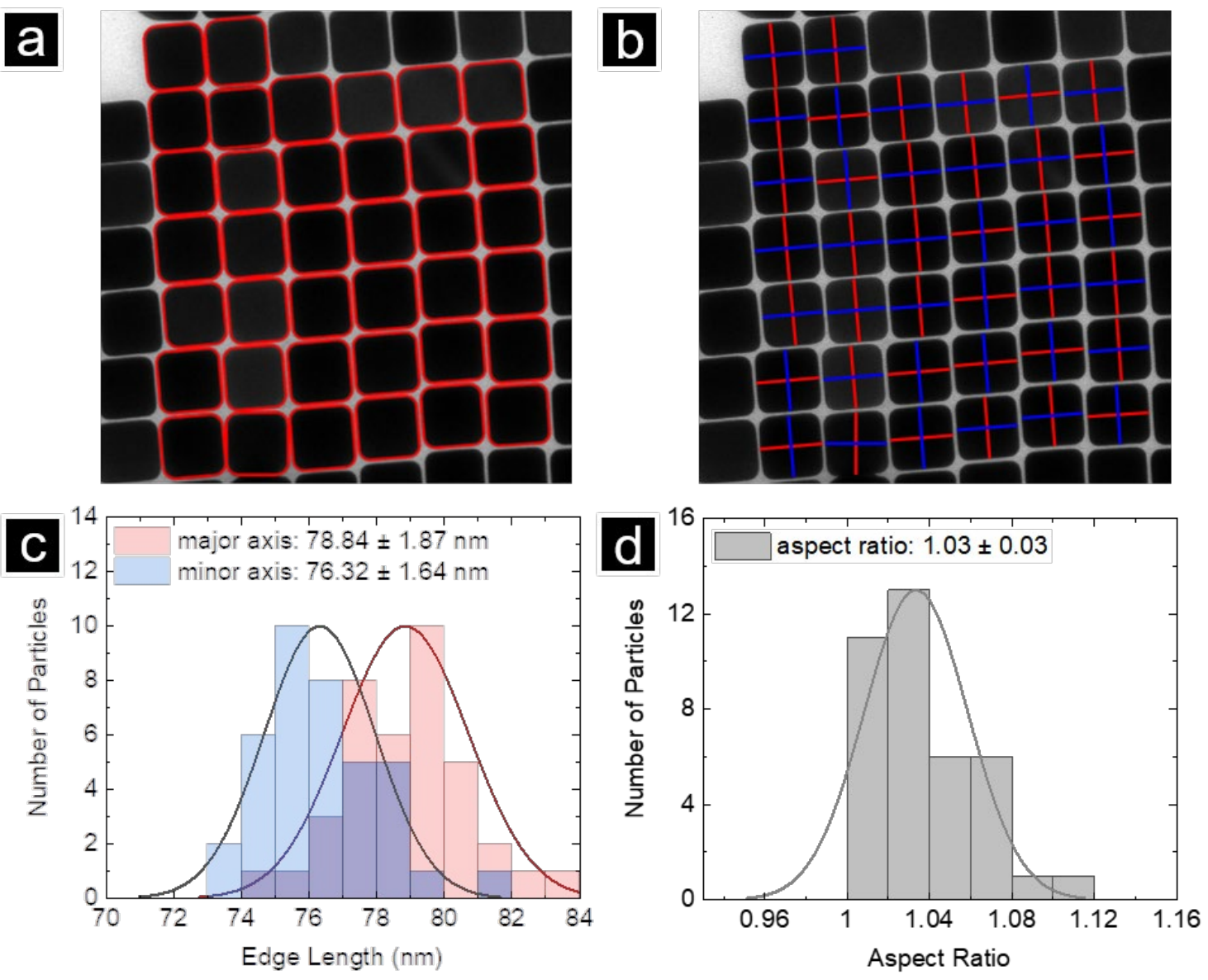

Figure S2. Representative analysis for the length of major and minor axes of Au NCs from TEM images via Matlab code. (a) Each Au NC was identified as a single entity by contour fitting. (b) Within the fixed contour, the longest axis was determined to the major axis, and the perpendicular axis was measured as the minor axis. (c) The average lengths of the major and minor axes were ca. 79 and ca. $76 \mathrm{~nm}$, respectively. (d) Aspect ratio of each NC was acquired through dividing the major by the minor axis. The average aspect ratio was ca. 1.03, indicating the Au NCs were nearly cubic shape. 


\section{FT-IR Spectroscopy Measurements to Optimize Methanol Washing}

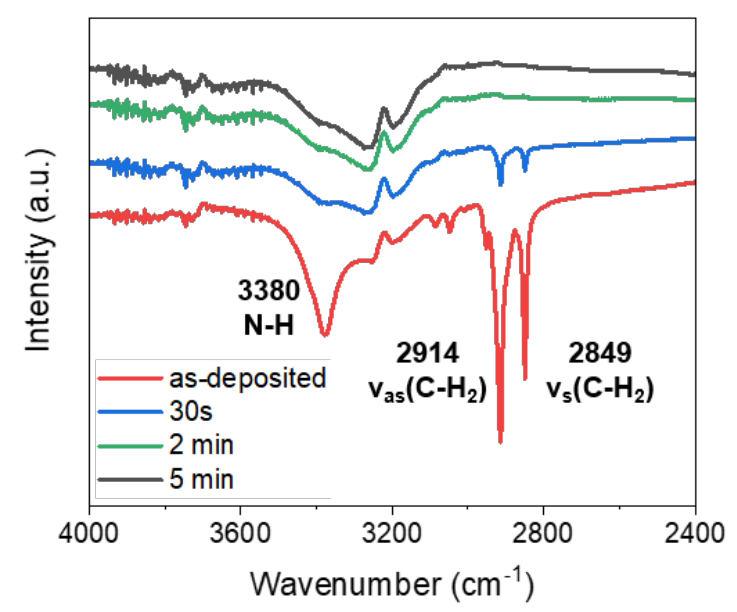

Figure S3. FT-IR spectra of drop-cast Au NCs coated silica substrate (red) and after MeOH-wash with methanol for 30 seconds (blue), 2 min (green) and 5 min (black). Symmetric and asymmetric C-H stretching vibration peaks were observed at $2849 \mathrm{~cm}^{-1}$ and $2914 \mathrm{~cm}^{-1}$, respectively. The C-H stretching signals were not visible after methanol treatments longer than 2 minutes. 


\section{In Situ AFM Operation}
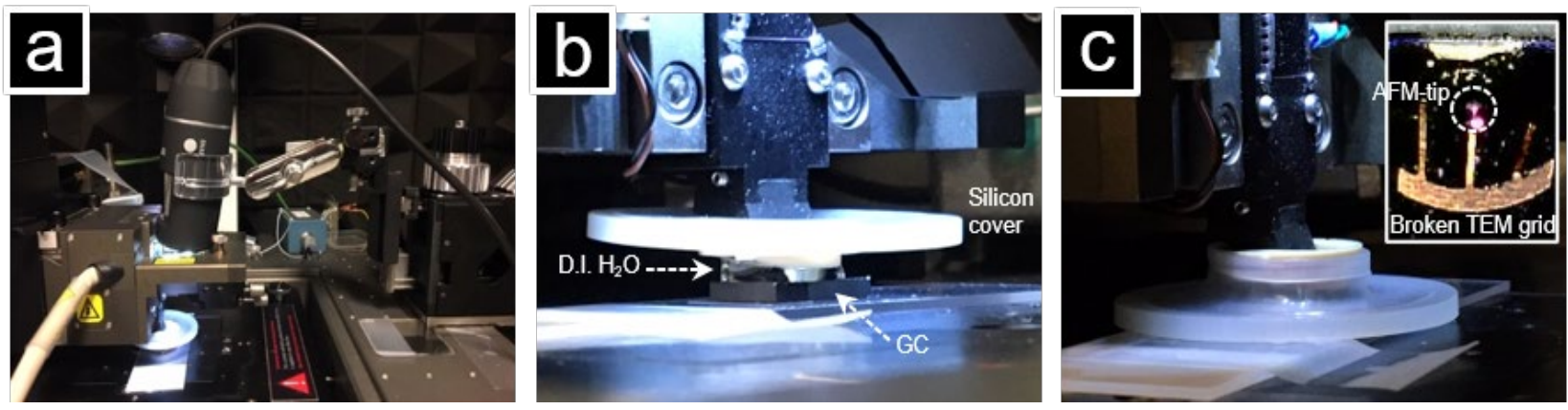

Figure S4. Photographs of in situ AFM operation and imaging position alignment. (a) Instrumentation for the in situ AFM with a top-view digital microscope. (b) AFM imaging within a droplet $(200 \mu \mathrm{L})$ of $\mathrm{H}_{2} \mathrm{O}$. (c) The AFM imaging area was sealed by thin silicon cover to prevent evaporation of $\mathrm{H}_{2} \mathrm{O}$. TEM grid was placed on the top of Au NC deposited GC, allowing the AFM tip to position at the targeted correlative imaging location (inset of c). 


\section{Scanning Electron Microscopy Measurements of Au NCs}

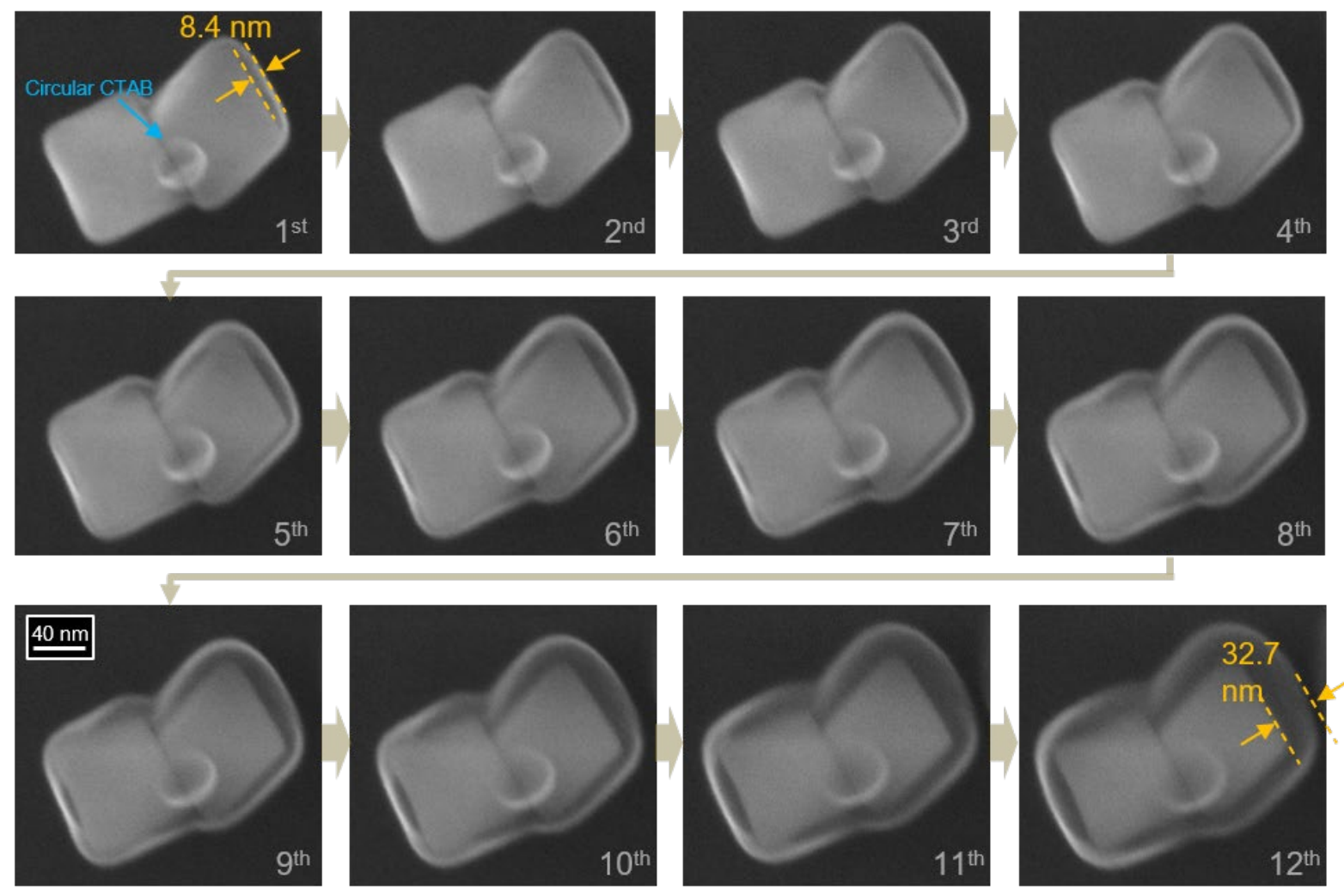

Figure S5. Electron micrograph of CTAB transformation by electron beam exposure during SEM imaging, adsorbed on the surface of gold nano-octahedron (Au ODs). Synthesized Au ODs solution was drop-cast on a freshly polished and cleaned glassy carbon substrate. The electron micrographs were acquired by operating with $20 \mathrm{kV}$ of electron high tension (EHT), $10 \mu \mathrm{m}$ aperture size, and $2.9 \mathrm{~mm}$ working distance. The time interval was 30 seconds between each image. The CTAB thickness (marked in orange dash line) increased from $8.4 \mathrm{~nm}$ to 32.7 $\mathrm{nm}$ after about 5 minutes. A circular CTAB, adhered on the top surface (marked in blue) also was swollen in same trend, indicating the volume of CTAB layer surrounding Au ODs was enlarged by the interaction with energy of electron beam, rather than melting down. 

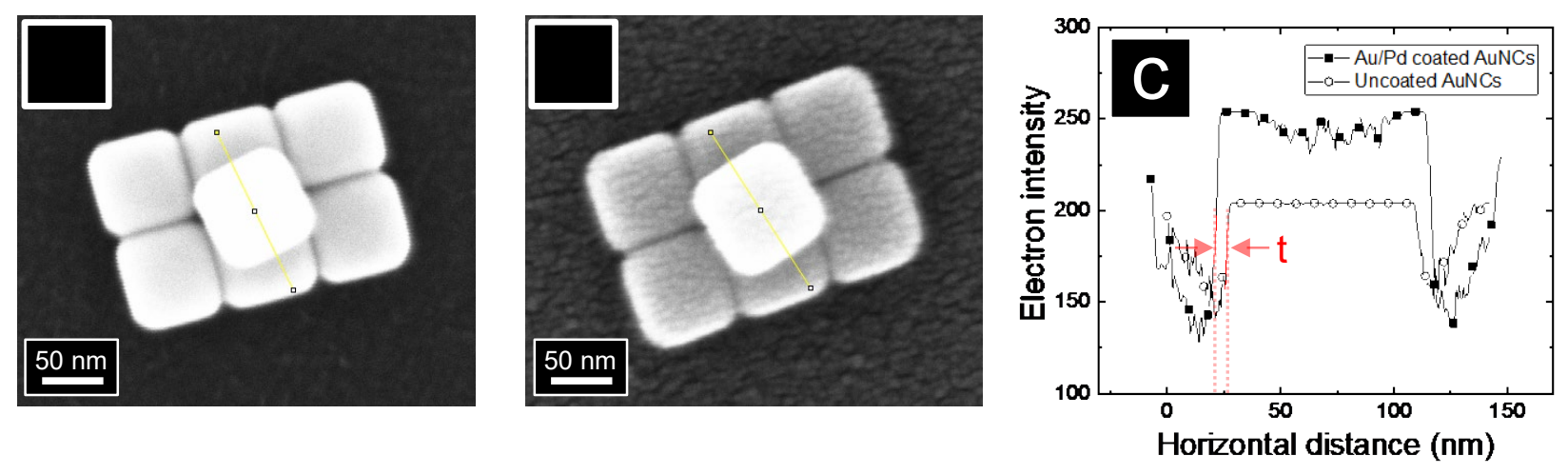

Figure S6. Measurement of $\mathrm{Au} / \mathrm{Pd}$ coating layer thickness on $\mathrm{Au} \mathrm{NCs}$. The difference of width between (a) before and (b) after $\mathrm{Au} / \mathrm{Pd}$ coating on single EC-cleaned $\mathrm{Au} \mathrm{NC}$ was measured from cross-sectional line profiles (c). The $\mathrm{Au} / \mathrm{Pd}$ layer thickness was $5.1 \mathrm{~nm}$ (marked as ' $\mathrm{t}$ ' in $\mathrm{c}$ ). The electron micrographs were taken by in-lens detector. Drop-cast Au NCs sample was coated together with EC-cleaned Au NCs. 

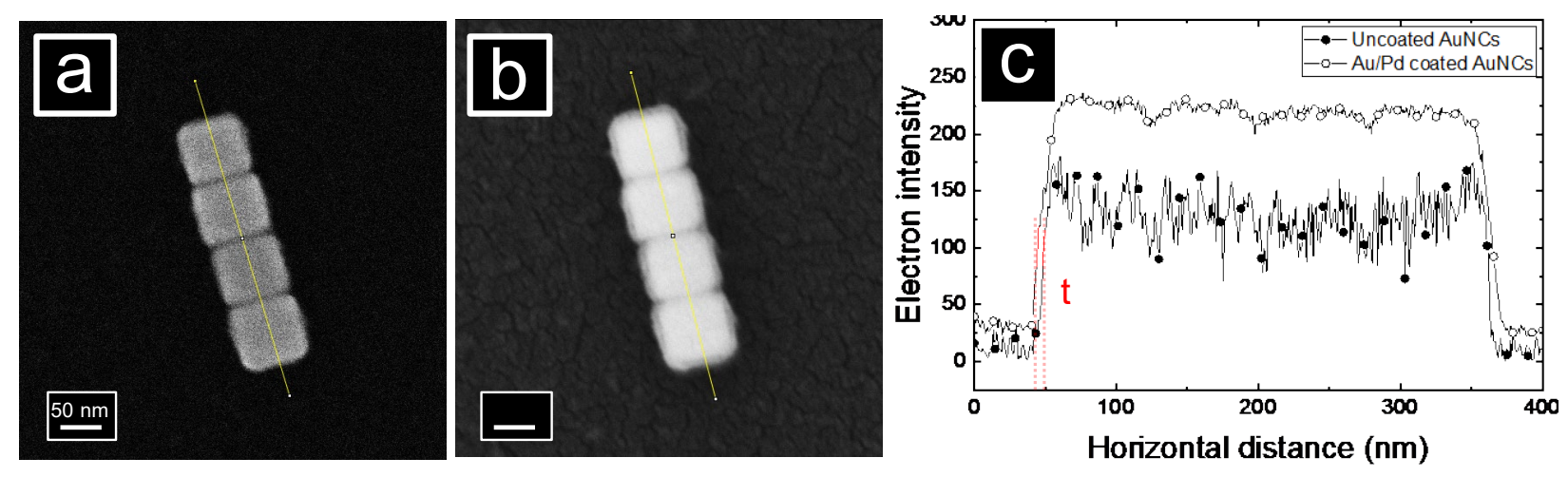

Figure S7. Measurement of $\mathrm{Au} / \mathrm{Pd}$ coating layer thickness on $\mathrm{MeOH}$-washed $\mathrm{Au}$ NCs. The width difference between (a) before and (b) after $\mathrm{Au} / \mathrm{Pd}$ coating on an assembly of four Au NCs was measured from cross-sectional line profiles (c). The thickness of Au/Pd coating was $5.6 \mathrm{~nm}$ (marked as ' $t$ ' in c). The electron micrographs of (a) and (b) were taken by in-lens and ET detectors, respectively. 

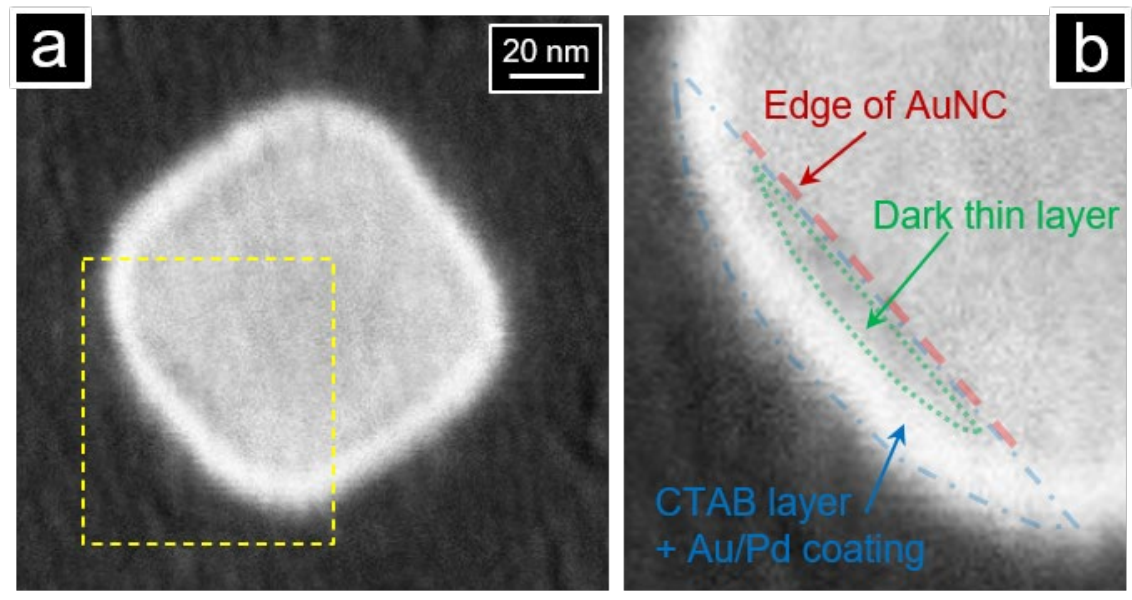

Figure S8. (a) Electron micrographs of a single drop-cast $\mathrm{Au} \mathrm{NC}$ after $\mathrm{Au} / \mathrm{Pd}$ coating. (b) Magnified view of Au NC (yellow box in a), presenting one side of Au NC. From the electron micrograph, the edge of core Au NC is identified (red dashed line in b). The outermost layer is composite layer of $\mathrm{Au} / \mathrm{Pd}$ coating and surface $\mathrm{CTAB}$ ligands (blue dashed line in $\mathrm{b}$ ). The darker region at the interface of $\mathrm{Au} \mathrm{NC}$ and $\mathrm{Au} / \mathrm{Pd}$ coating layer is consisted solely of the $\mathrm{CTAB}$ ligands. 


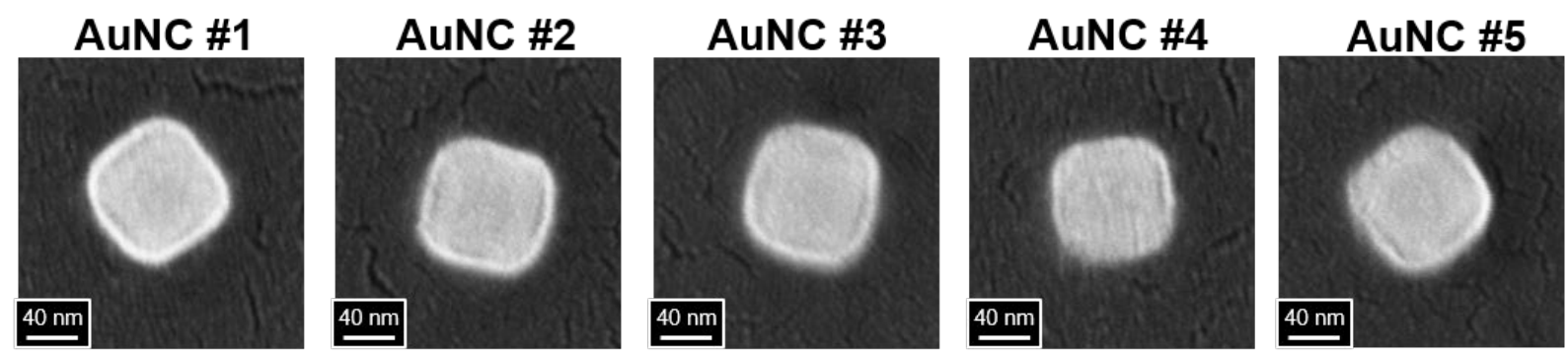

\section{Measurement example of AuNC \#1}

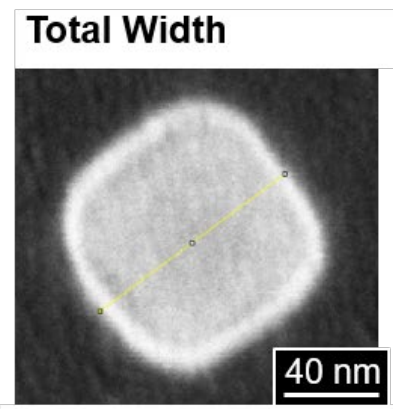

a. $97.7 \mathrm{~nm}$

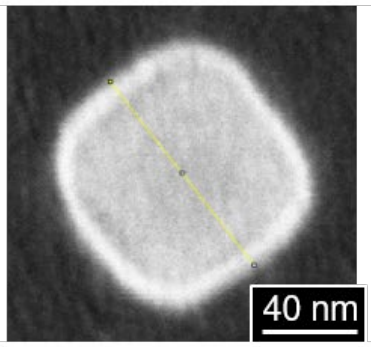

b. $100.9 \mathrm{~nm}$
Edge length (core Au NC)

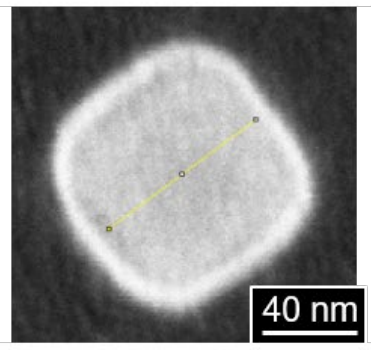

a. $78.4 \mathrm{~nm}$

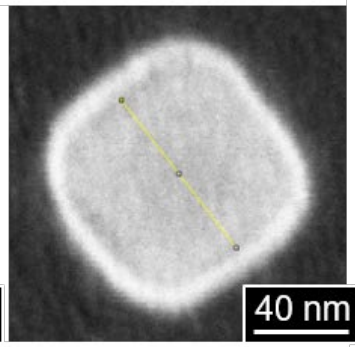

b. $78.8 \mathrm{~nm}$

CTAB thickness + Conductive coating

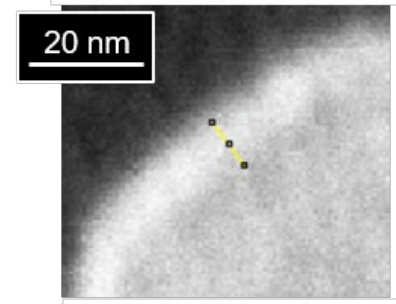

layer a. $9.82 \mathrm{~nm}$

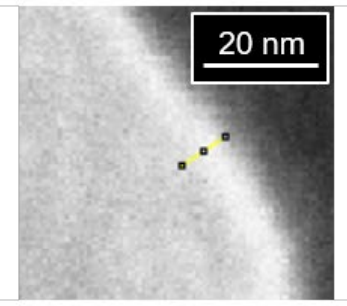

layer b. $8.42 \mathrm{~nm}$

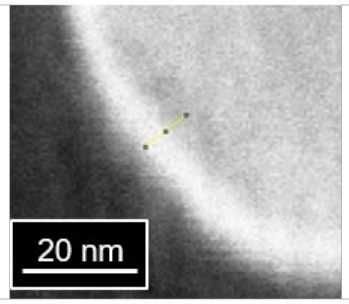

layer c. $10.4 \mathrm{~nm}$

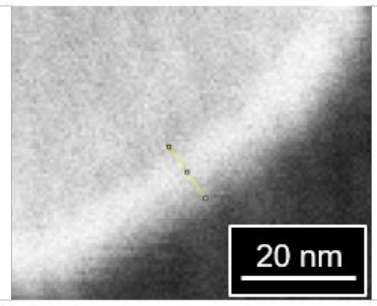

layer d. $10.6 \mathrm{~nm}$

Figure S9. SEM images of drop-cast Au NCs utilized to quantify CTAB layer thickness. Among five $\mathrm{Au}$ NCs, the thickness estimation of Au NC\#1 was shown as a typical example. Each Au NC was measured in two perpendicular axes along with yellow lines. In each direction, the total width of drop-cast $\mathrm{Au} \mathrm{NC}$ and the width of core Au NC (edge length) was measured separately (a and b). And the layer including $\mathrm{Au} / \mathrm{Pd}$ coating layer and outer CTAB ligands were measured at four faces individually (layer a, b, c and d). The Au/Pd coating thickness on each Au NC was ca. 5.1 nm. 
Table S1. The CTAB layer thickness on drop-cast Au NCs measured from the electron micrographs in Figure S9. The thickness of $\mathrm{Au} / \mathrm{Pd}$ conductive coating layer (ca. $5.1 \mathrm{~nm}$ ) is subtracted from the thickness of outer layer. (unit: $\mathrm{nm}$ )

\begin{tabular}{|c|c|c|c|c|c|c|}
\hline No. of Au NC & $\# 1$ & $\# 2$ & $\# \mathbf{3}$ & $\# 4$ & $\# 5$ & Average \\
\hline $\begin{array}{c}\text { Width a } \\
\text { (Au NC core }+ \text { CTAB }+ \\
\text { Au/Pd coating) }\end{array}$ & 97.7 & 102.5 & 105.1 & 94.4 & 102.4 & $100.4 \pm 3.8$ \\
\hline $\begin{array}{c}\text { Width b } \\
\text { (Au NC core }+ \text { CTAB + } \\
\text { Au/Pd coating) }\end{array}$ & 100.9 & 104 & 101.8 & 95.2 & 103.4 & $101.1 \pm 3.1$ \\
\hline $\begin{array}{c}\text { Width a } \\
\text { (core Au NC) }\end{array}$ & 78.4 & 84.7 & 84.8 & 75.1 & 81.9 & $81.0 \pm 3.8$ \\
\hline $\begin{array}{c}\text { Width b } \\
\text { (core Au NC) }\end{array}$ & 78.8 & 82.2 & 79.8 & 80.1 & 76.3 & $79.4 \pm 1.9$ \\
\hline $\begin{array}{c}\text { CTAB thickness } \\
\text { layer a }\end{array}$ & 4.7 & 3.0 & 5.7 & 3.7 & 4.9 & \multirow{4}{*}{$4.2 \pm 1.6$} \\
\hline $\begin{array}{l}\text { CTAB thickness } \\
\text { layer b }\end{array}$ & 3.3 & 0.5 & 4.1 & 2.3 & 5.5 & \\
\hline $\begin{array}{l}\text { CTAB thickness } \\
\text { layer c }\end{array}$ & 5.3 & 6.6 & 3.0 & 1.9 & 4.5 & \\
\hline $\begin{array}{c}\text { CTAB thickness } \\
\text { layer d }\end{array}$ & 5.5 & 6.6 & 4.6 & 2.6 & 4.8 & \\
\hline
\end{tabular}



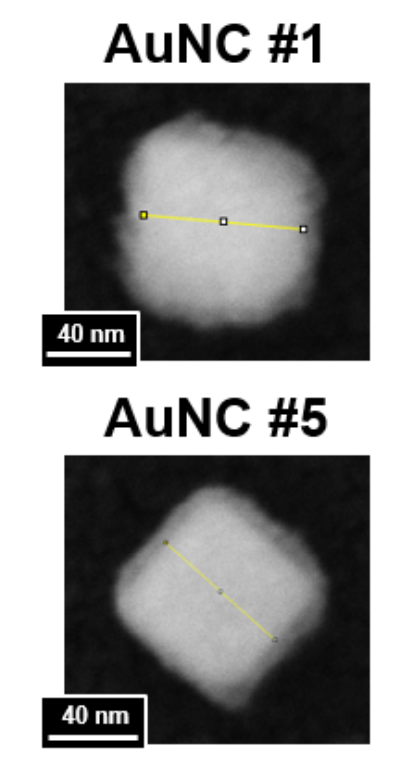

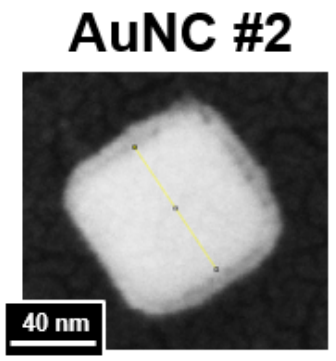

AuNC \#6

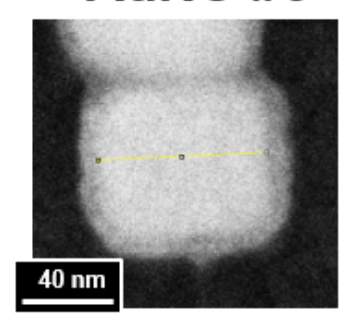

AuNC \#3

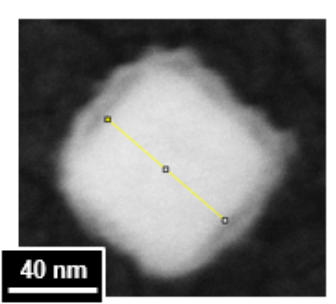

AuNC \#7

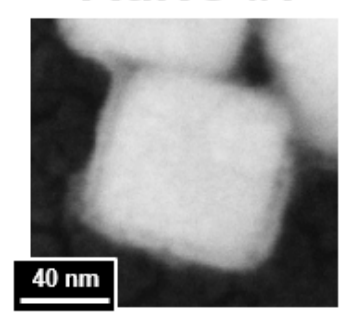

AuNC \#4

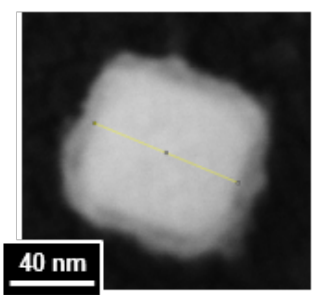

AuNC \#8

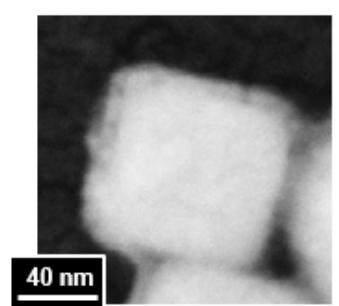

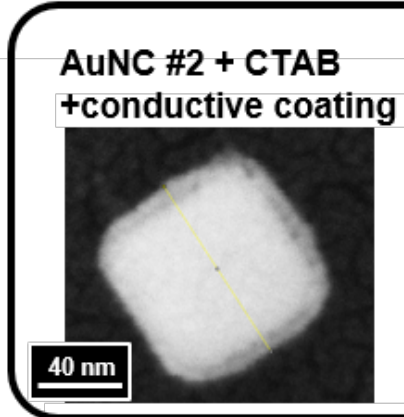

Edge length

CTAB thickness + Conductive coating

of AuNC\#2

layer a. layer $\mathrm{b}$. layer $\mathrm{c}$.
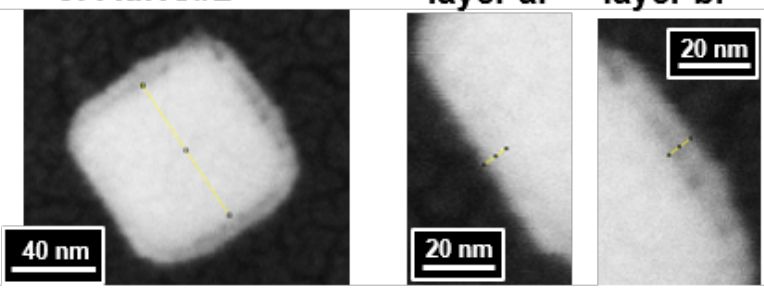

$20 \mathrm{~nm}$

layer d.

$20 \mathrm{~nm}$

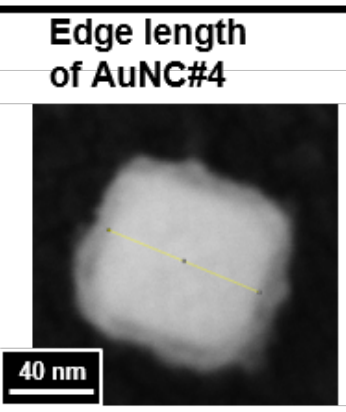

CTAB thickness + Conductive coating

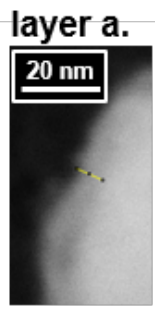

layer $\mathrm{c}$.

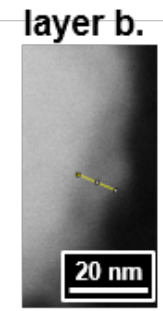

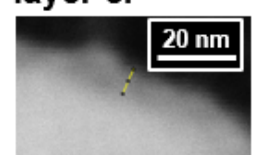

layer $\mathrm{d}$.

Figure S10. SEM images of MeOH-washed Au NCs utilized to quantify CTAB layer thickness. Among eight $\mathrm{Au} \mathrm{NCs,} \mathrm{the} \mathrm{thickness} \mathrm{estimation} \mathrm{of} \mathrm{Au} \mathrm{NC \# 2} \mathrm{and} \mathrm{\# 4} \mathrm{were} \mathrm{shown} \mathrm{as} \mathrm{typical}$ examples. Each $\mathrm{Au} \mathrm{NC}$ was measured along with yellow lines. In each $\mathrm{Au} \mathrm{NC}$, the total width of $\mathrm{MeOH}$-washed $\mathrm{Au} \mathrm{NC}$ and the width of core Au NC (edge length) were measured separately. And the layer including $\mathrm{Au} / \mathrm{Pd}$ coating layer and outer $\mathrm{CTAB}$ ligands were measured at four faces individually (layer a, b, c and d). 
Table S2. The CTAB layer thickness on $\mathrm{MeOH}$-washed $\mathrm{Au}$ NCs measured from the electron micrographs in Figure S10. The thickness of Au/Pd conductive coating layer (ca. $5.6 \mathrm{~nm}$ ) is subtracted from the thickness of outer layer. (unit: $\mathrm{nm}$ )

\begin{tabular}{|c|c|c|c|c|c|c|c|c|c|}
\hline No. of AuNC & $\# 1$ & $\# 2$ & $\# \mathbf{3}$ & $\# 4$ & $\# 5$ & \#6 & $\# 7$ & $\# \mathbf{8}$ & Average \\
\hline $\begin{array}{c}\text { Au NC core }+ \text { CTAB } \\
+ \text { Au/Pd coating }\end{array}$ & 103.2 & 97.1 & 100.4 & 96.2 & 96.1 & 99.9 & 94.9 & 89.4 & $97.2 \pm 3.9$ \\
\hline Width of Au NC core & 79.8 & 77.8 & 77.9 & 76.2 & 76.9 & 79.6 & 74.9 & 73.8 & $77.6 \pm 1.6$ \\
\hline $\begin{array}{c}\text { CTAB thickness } \\
\text { layer a }\end{array}$ & 3.6 & 2.5 & 4.9 & 2.4 & 1.7 & 2.3 & 1.6 & 6.2 & \multirow{4}{*}{$3.0 \pm 1.3$} \\
\hline $\begin{array}{l}\text { CTAB thickness } \\
\text { layer b }\end{array}$ & 3.9 & 1.5 & 3.4 & 5.6 & 4.8 & 4.3 & 1.7 & 1.5 & \\
\hline $\begin{array}{l}\text { CTAB thickness } \\
\text { layer c }\end{array}$ & 3.8 & 3.0 & 2.6 & 2.7 & 4.6 & - & - & - & \\
\hline $\begin{array}{c}\text { CTAB thickness } \\
\text { layer } d\end{array}$ & 2.1 & 2.3 & 2.1 & 3.5 & 2.6 & 2.3 & 1.6 & - & \\
\hline
\end{tabular}



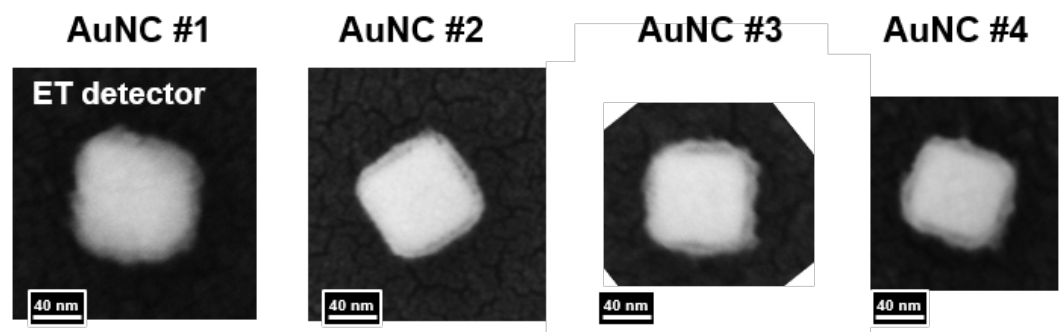

AuNC \#5

AuNC \#6
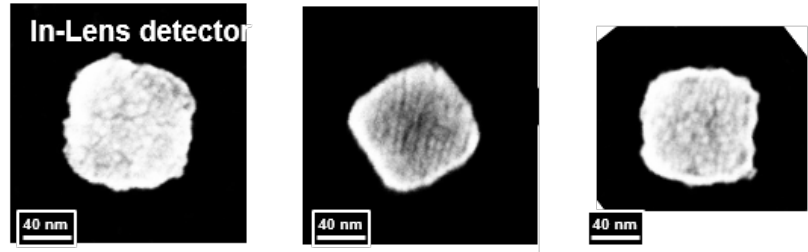

$40 \mathrm{~nm}$
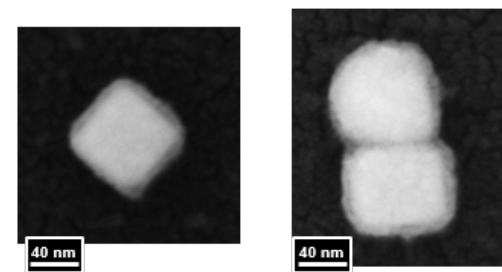

AuNC \#7 \& 8
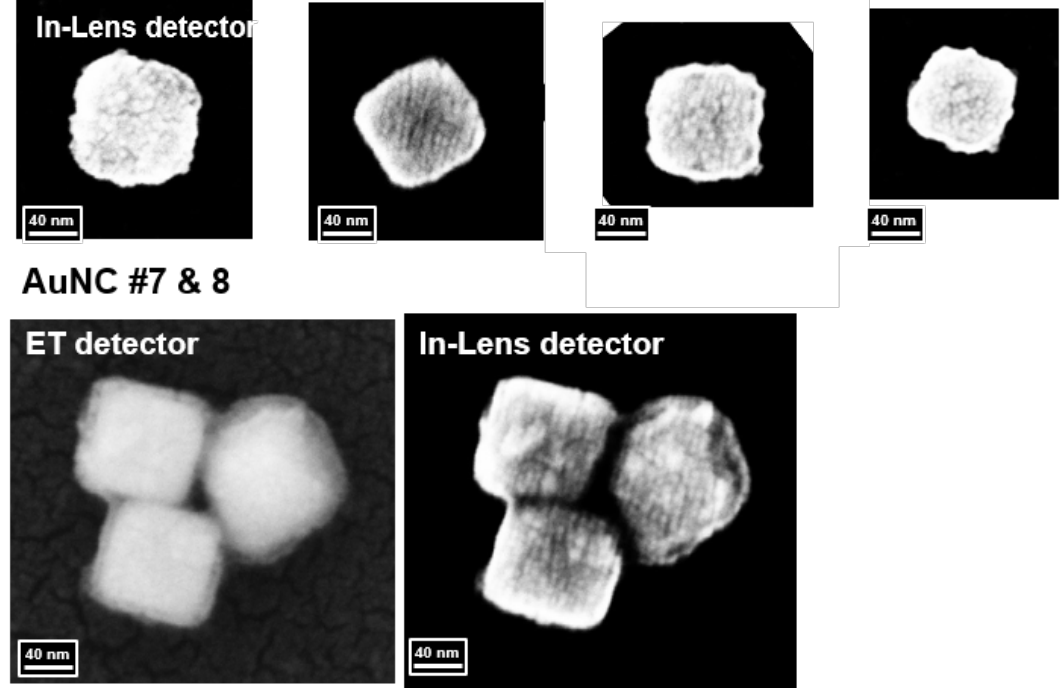

40nm
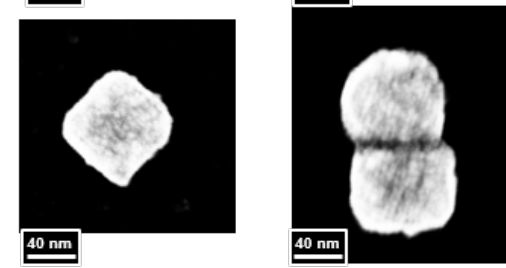

Figure S11. Electron micrographs of $\mathrm{MeOH}$-washed $\mathrm{Au} \mathrm{NCs}$ measured by ET and in-lens detectors. The contrast difference between the outer layers, composed of CTAB ligands and $\mathrm{Au} / \mathrm{Pd}$ coating, and core $\mathrm{Au} \mathrm{NC}$ was clearer from the image recorded by ET detector than in-lens detector. 


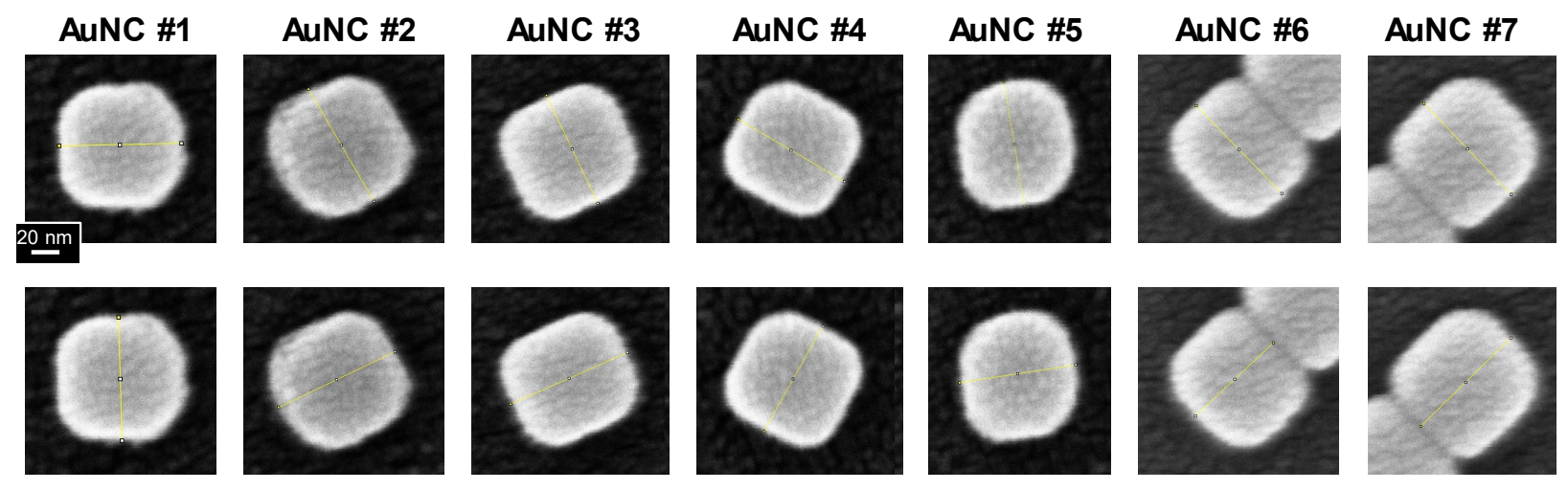

Figure S12. SEM images of EC-cleaned Au NCs utilized to quantify CTAB layer thickness. The width of individual $\mathrm{Au}$ NCs were measured in both perpendicular directions (upper and lower lanes above). The estimated $\mathrm{Au} / \mathrm{Pd}$ coating layer thickness was ca. $5.1 \mathrm{~nm}$. All electron micrographs are in identical magnification and measured by in-lens detector. 
Table S3. The width measurement of EC-cleaned $\mathrm{Au}$ NCs from the electron micrographs in Figure S12. The thickness of $\mathrm{Au} / \mathrm{Pd}$ conductive coating layer (ca. $5.1 \mathrm{~nm}$ ) is subtracted from the width measurement of $\mathrm{Au} \mathrm{NC}$ in both perpendicular axes (a and b). (unit: nm)

\begin{tabular}{|c|c|c|c|c|c|c|c|c|}
\hline No. of Au NC & $\# 1$ & $\# 2$ & $\# \mathbf{3}$ & $\# 4$ & \#5 & $\# 6$ & $\# 7$ & Average \\
\hline $\begin{array}{c}\text { AuNC+coating } \\
\text { direction a }\end{array}$ & 87.7 & 90.6 & 83.9 & 92.1 & 89.3 & 88.3 & 89.4 & $88.7 \pm 2.4$ \\
\hline $\begin{array}{c}\text { Width of AuNC } \\
\text { without coating } \\
\text { layer } \\
\text { direction a }\end{array}$ & 77.5 & 80.4 & 73.7 & 81.9 & 79.1 & 78.1 & 79.2 & $78.6 \pm 2.4$ \\
\hline $\begin{array}{c}\text { AuNC+coating } \\
\text { direction b }\end{array}$ & 87.3 & 93.2 & 90.2 & 89.7 & 83.5 & 77.7 & 90.5 & $87.4 \pm 4.8$ \\
\hline $\begin{array}{c}\text { Width of AuNC } \\
\text { without coating } \\
\text { layer } \\
\text { direction b }\end{array}$ & 77.1 & 83.0 & 80.0 & 79.5 & 73.3 & 72.6 & 85.4 & $78.7 \pm 4.4$ \\
\hline
\end{tabular}


5. In Situ AFM Measurements of Au NCs
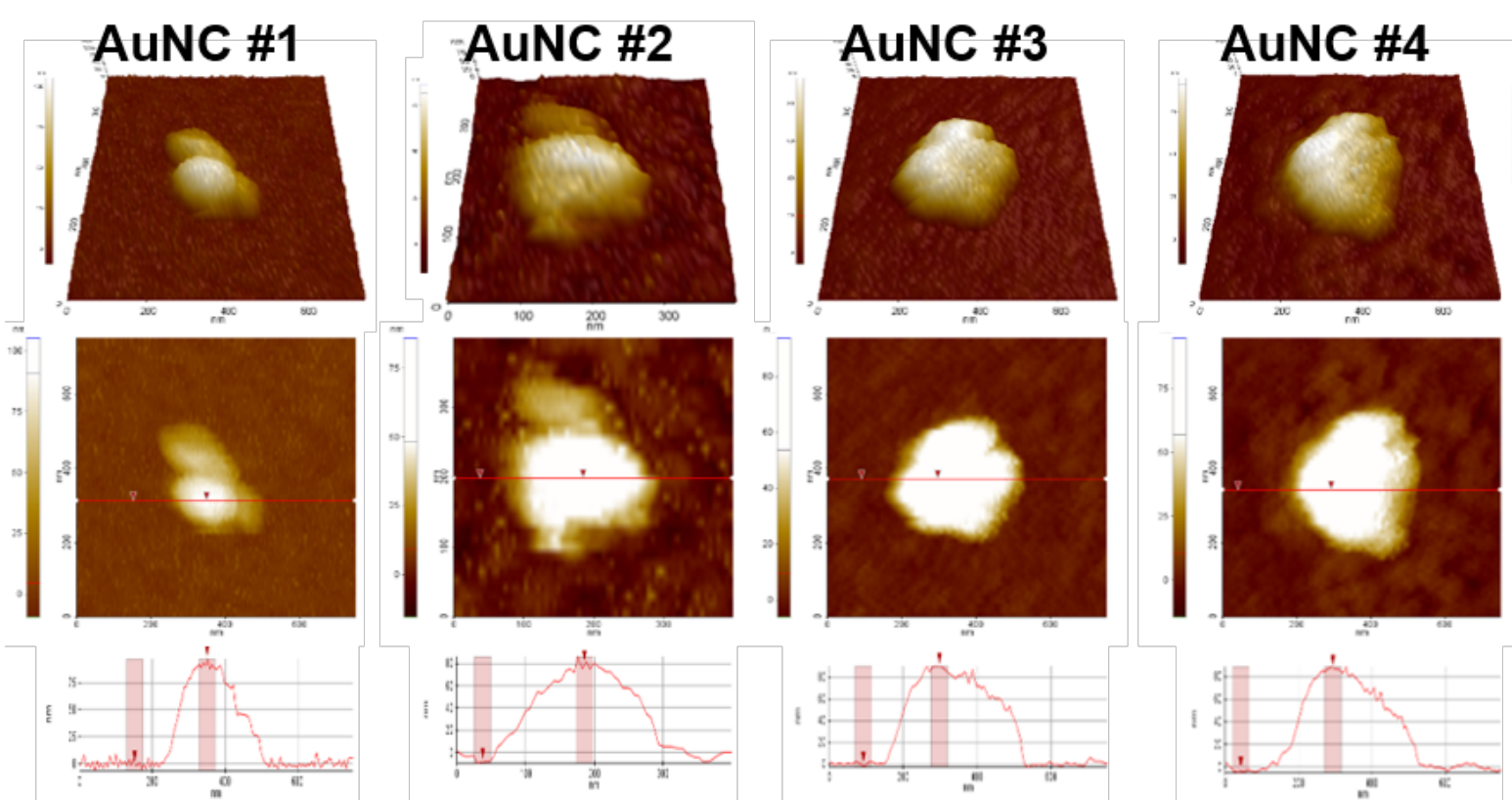
\begin{tabular}{l|l|l}
\hline Height: $91.5 \mathrm{~nm}$ \\
FWHM: $181 \mathrm{~nm}$
\end{tabular}$\quad \approx \quad \begin{aligned} & \text { Height: } 86.8 \mathrm{~nm} \\
& \text { FWHM : } 170 \mathrm{~nm}\end{aligned}$

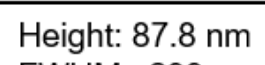
FWHM : $299 \mathrm{~nm}$
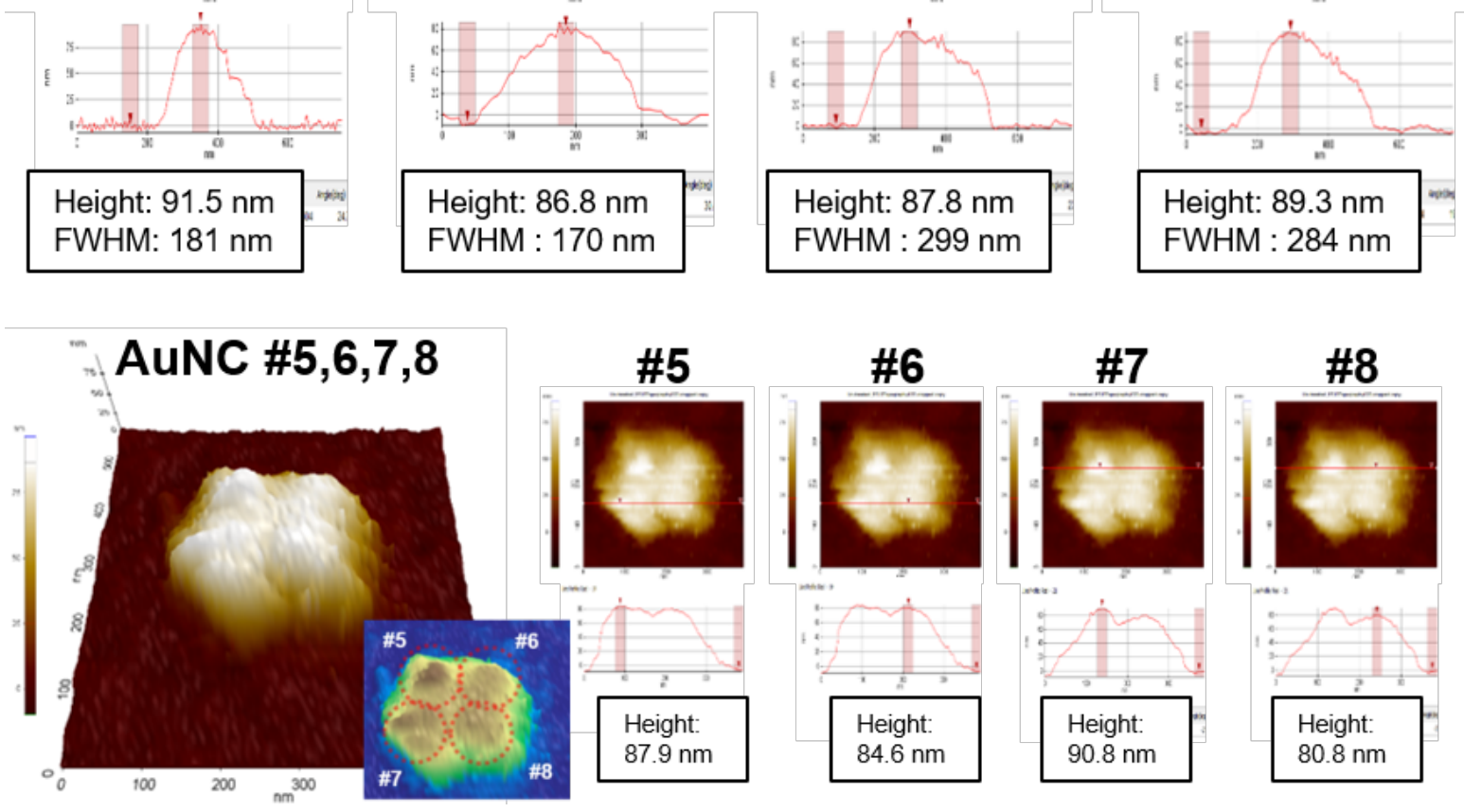

Figure S13. In situ AFM topographies of eight drop-cast Au NCs to measure maximum height and FWHM. 
Table S4. Maximum height and FWHM measurements from AFM topographies of drop-cast Au NCs in Figure S13.

\begin{tabular}{cccccccccc}
\hline No. of Au NC & $\# 1$ & $\# 2$ & $\# 3$ & $\# 4$ & $\# 5$ & $\# 6$ & $\# 7$ & $\# 8$ & Average \\
\hline $\begin{array}{c}\text { Maximum height } \\
(\mathbf{n m})\end{array}$ & 91.5 & 86.8 & 87.8 & 89.3 & 87.9 & 84.6 & 90.8 & 80.8 & $87.4 \pm 3.2$ \\
FWHM (nm) & 181 & 170 & 299 & 284 & - & - & - & - & $233.5 \pm 58.4$ \\
\hline
\end{tabular}



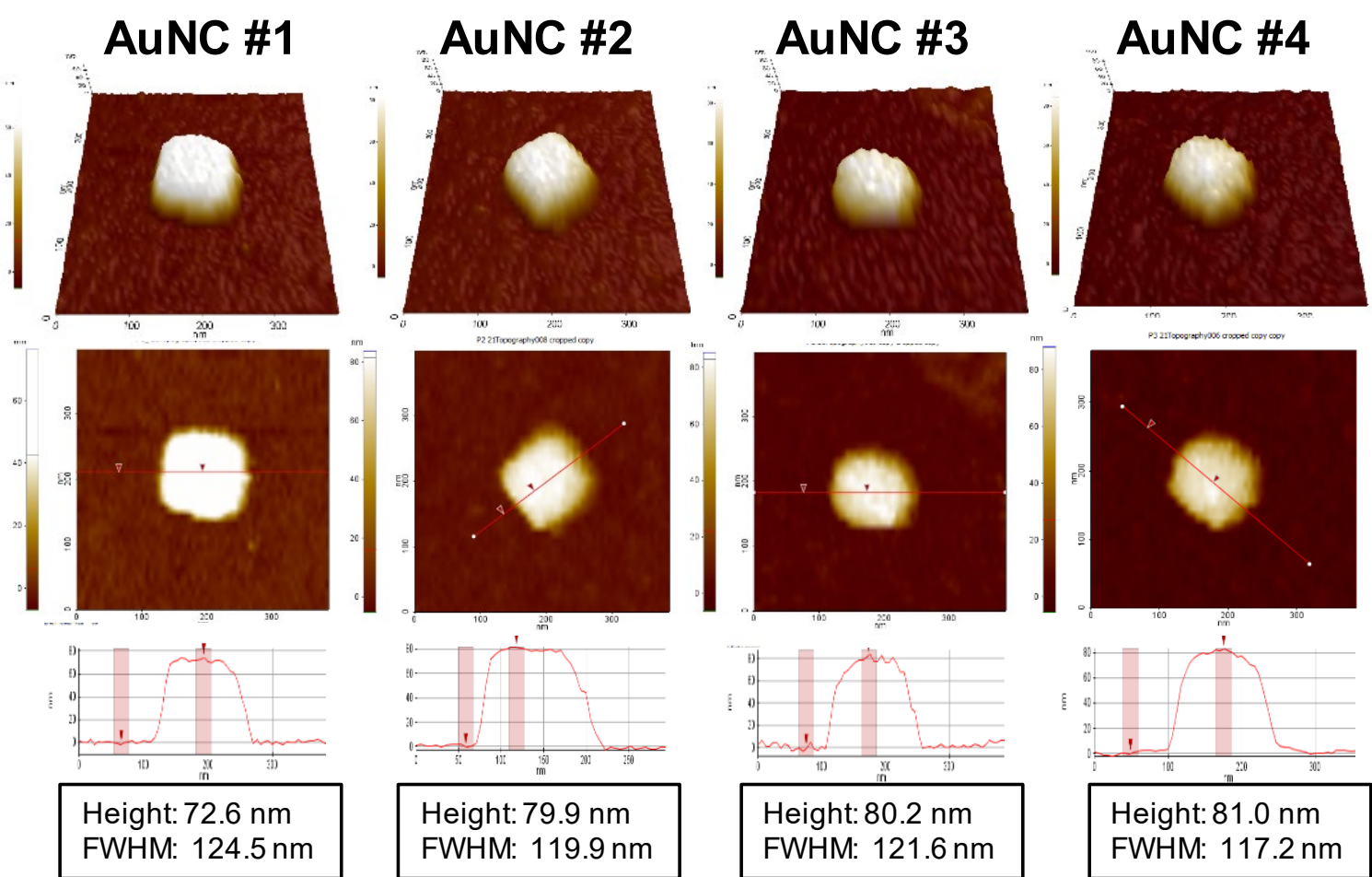

Height: $72.6 \mathrm{~nm}$ FWHM: $124.5 \mathrm{~nm}$
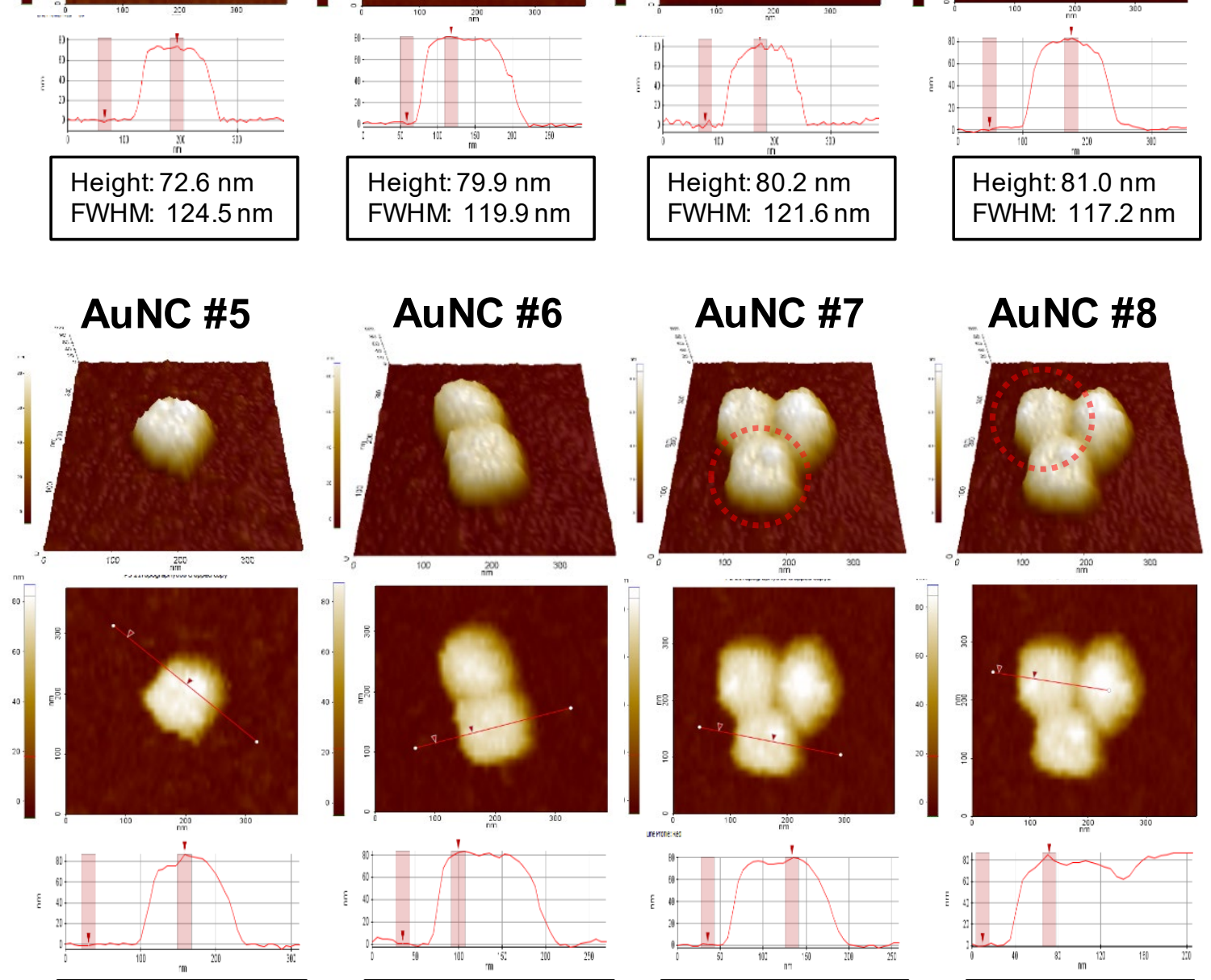

Height: $83.3 \mathrm{~nm}$ FWHM: $103.9 \mathrm{~nm}$

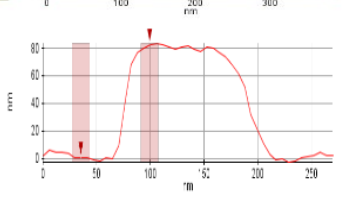

Height: $81.4 \mathrm{~nm}$ FWHM: $115.7 \mathrm{~nm}$

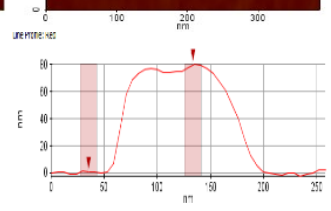

Height: $77.3 \mathrm{~nm}$ FWHM: $110.7 \mathrm{~nm}$

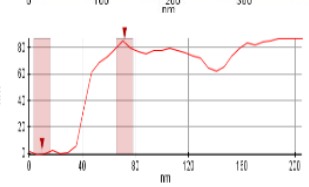

Height: $80.6 \mathrm{~nm}$

Figure S14. In situ AFM topographies of eight $\mathrm{MeOH}$-washed $\mathrm{Au} \mathrm{NCs}$ to measure maximum height and FWHM. 
Table S5. Maximum height and FWHM measurements from in situ AFM topography of MeOHwashed Au NCs in Figure S14.

\begin{tabular}{cccccccccc}
\hline $\begin{array}{c}\text { No. of Au } \\
\text { NCs }\end{array}$ & $\# \mathbf{1}$ & $\mathbf{\# 2}$ & $\mathbf{\# 3}$ & $\mathbf{\# 4}$ & $\mathbf{\# 5}$ & $\mathbf{\# 6}$ & $\mathbf{\# 7}$ & $\mathbf{\# 8}$ & Average \\
\hline $\begin{array}{c}\text { Maximum } \\
\text { height } \\
\mathbf{( n m )}\end{array}$ & 72.6 & 79.9 & 80.2 & 81 & 83.3 & 81.4 & 77.3 & 80.6 & $79.6( \pm 3.1)$ \\
$\begin{array}{c}\text { FWHM } \\
(\mathbf{n m})\end{array}$ & 124.5 & 119.9 & 121.6 & 117.2 & 103.9 & 115.7 & 110.7 & - & $135.6( \pm 6.5)$ \\
\hline
\end{tabular}




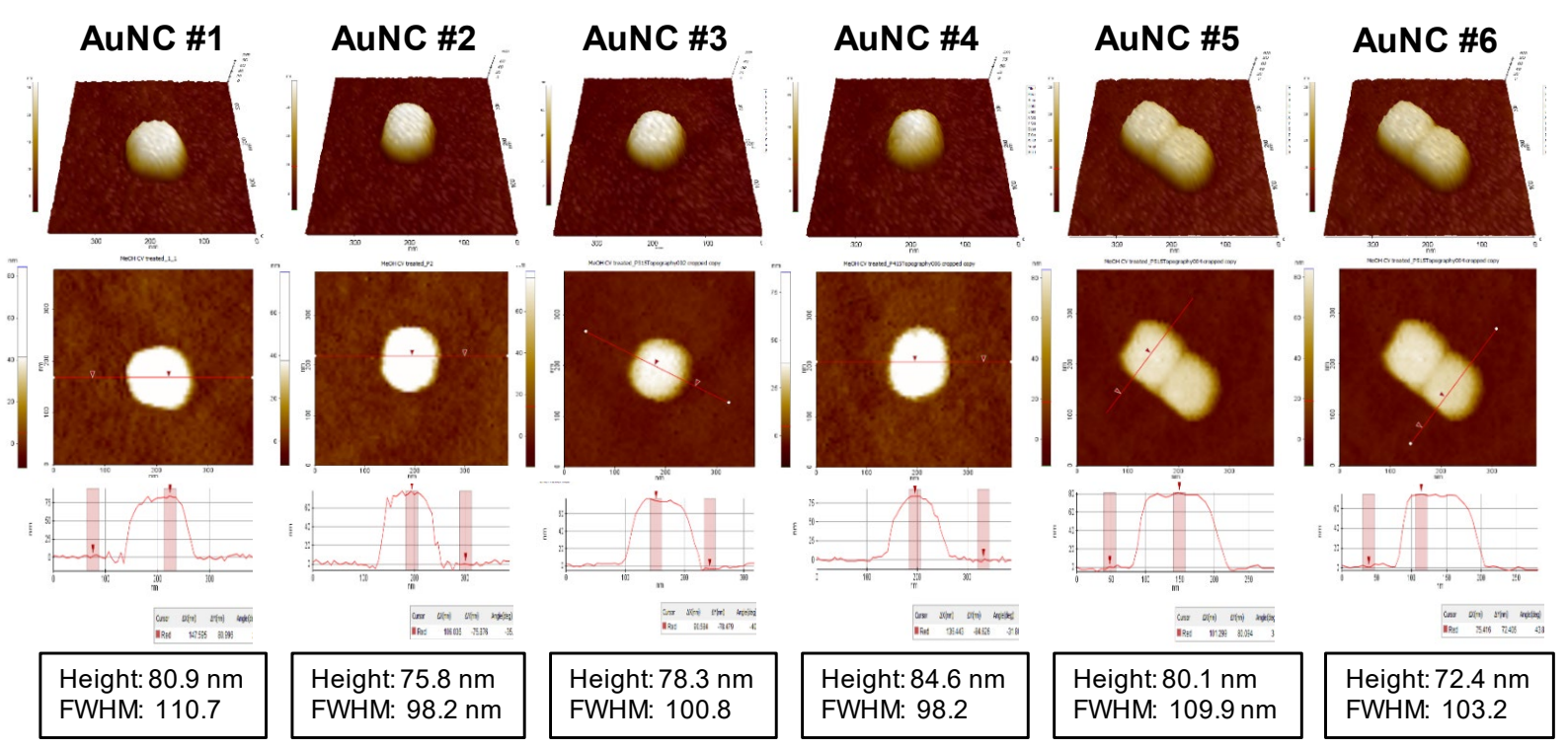

Figure S15. In situ AFM topographies of six EC-cleaned Au NCs to measure maximum height and FWHM. 
Table S6. Maximum height and FWHM measurements from in situ AFM topography of ECcleaned Au NCs in Figure S15.

\begin{tabular}{cccccccc}
\hline $\begin{array}{c}\text { No. of Au } \\
\text { NCs }\end{array}$ & $\# \mathbf{1}$ & $\mathbf{\# 2}$ & $\mathbf{\# 3}$ & $\mathbf{\# 4}$ & $\mathbf{\# 5}$ & $\mathbf{\# 6}$ & Average \\
\hline $\begin{array}{c}\text { Maximum } \\
\text { height (nm) }\end{array}$ & 80.9 & 75.8 & 78.3 & 84.6 & 80.1 & 72.4 & $78.8 \pm 3.7$ \\
\hline $\begin{array}{c}\text { FWHM } \\
\text { (nm) }\end{array}$ & 110.7 & 98.2 & 100.8 & 98.2 & 109.9 & 103.2 & $103.5 \pm 5.1$ \\
\hline
\end{tabular}


6. Sidewall Artifacts Analysis of In Situ AFM Topographies

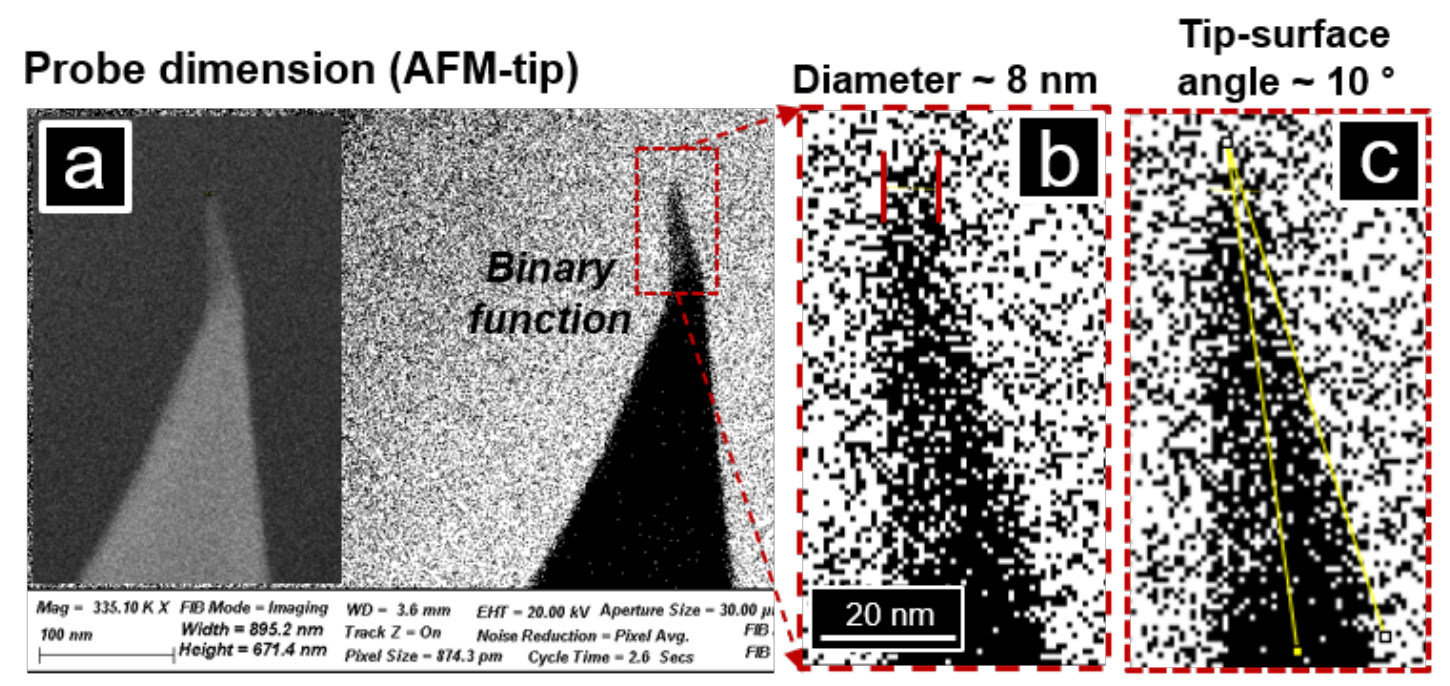

Figure S16. Estimation of AFM tip (BL-AC40TS-C2) dimension by SEM. Based on magnified view of (a) SEM image presenting overall geometry of AFM tip, (b) the tip-end diameter was ca. $8 \mathrm{~nm}$ and (c) the tip sidewall angle was ca. $10^{\circ}$. The SEM image of the AFM tip was taken without conductive coating on the surface. 
Tip radius $4 \mathrm{~nm}$

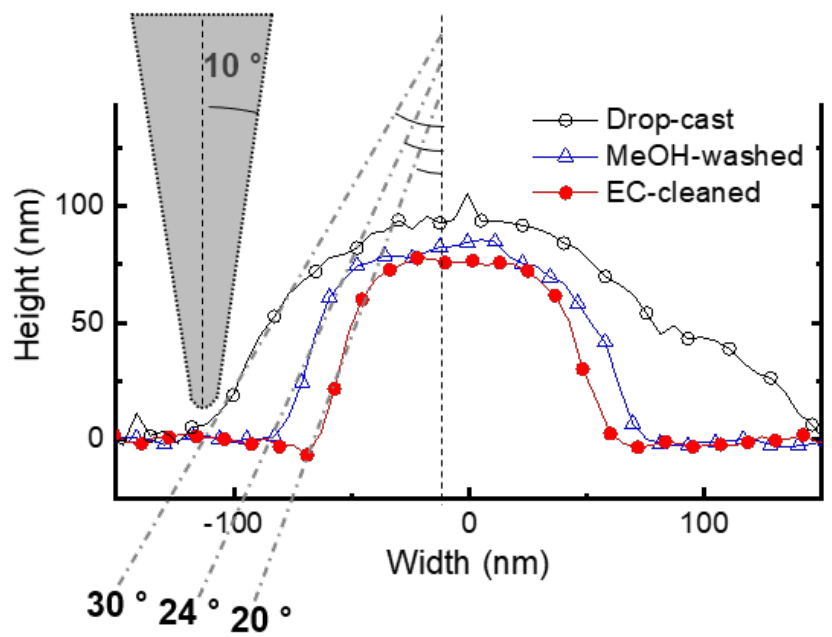

Figure S17. Measured side angles of the AFM topographies for the three Au NCs samples. The angles of sidewall of $\mathrm{Au}$ NCs compared to mathematical line at the center of Au NC (black dashed line) are $30^{\circ}, 24^{\circ}$, and $20^{\circ}$ for drop-cast, $\mathrm{MeOH}$-washed, and EC-cleaned Au NCs, respectively. Compared to the model AFM tip with $4 \mathrm{~nm}$ tip radius and $10^{\circ}$ tip angle (gray illustration on left), all the sidewall angles measured from three different Au NCs showed greater values. 

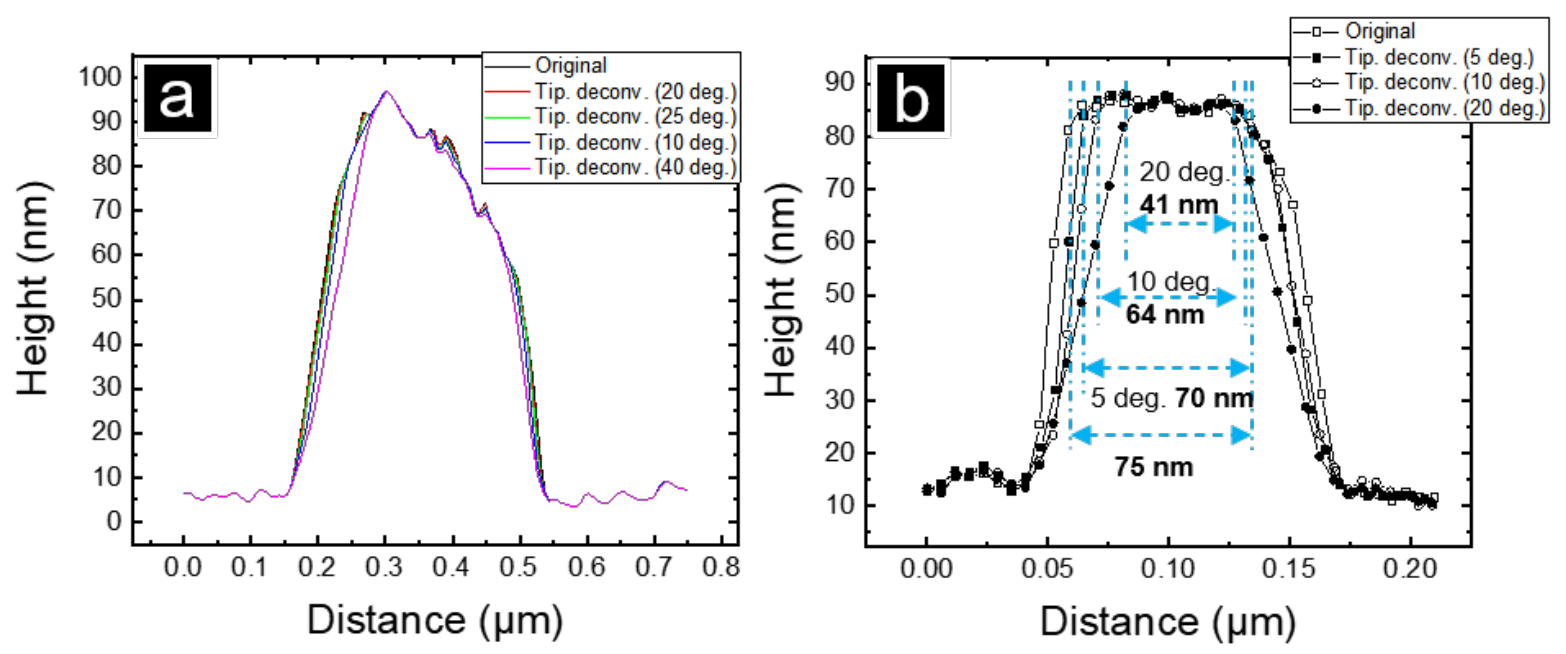

Figure S18. AFM tip-deconvolution test. Cross-sectional line profiles of AFM topographies simulated from (a) drop-cast and (b) EC-cleaned Au NCs by AFM tip with $8 \mathrm{~nm}$ diameter and varied tip-sidewall angles from 5 to $40^{\circ}$. 
7. Correlative SEM and In Situ AFM Measurements and Data Analysis
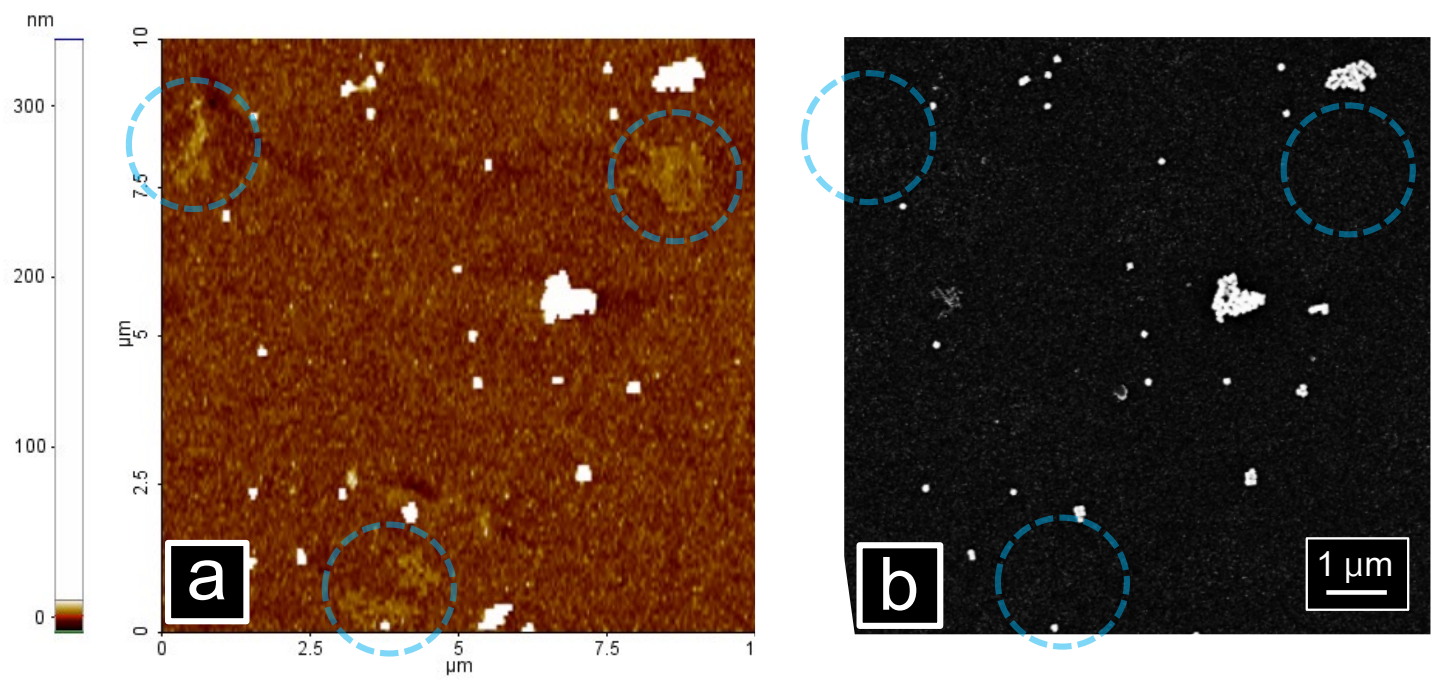

Figure S19. AFM topography (a) and SEM image (b) of MeOH-washed Au NCs measured at the same position (scanning area $10 \mu \mathrm{m} \times 10 \mu \mathrm{m}$ ). The CTAB residues are observed from AFM topography, but not detected in SEM image (blue dashed circles). 

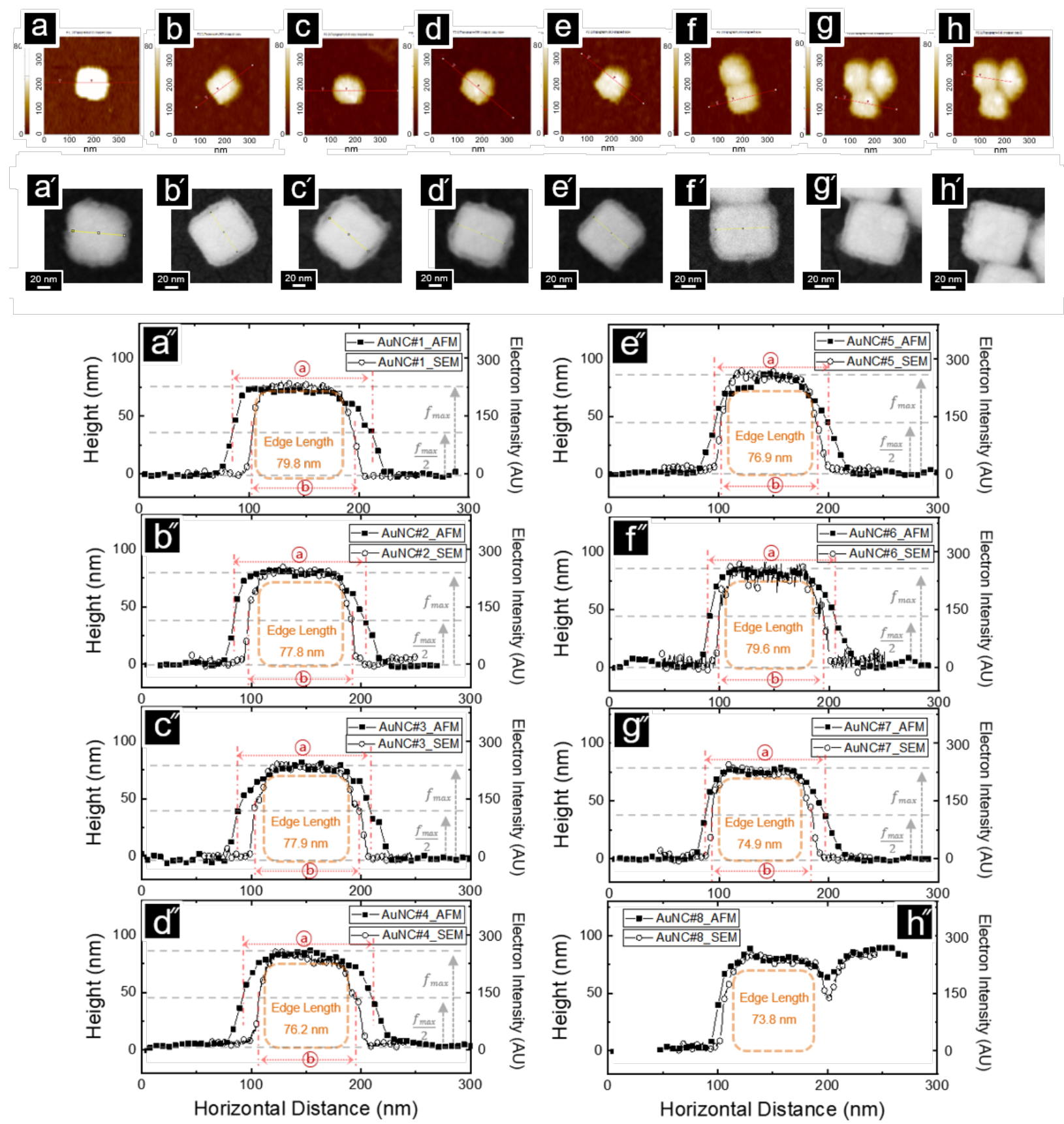

Figure S20. Correlative analysis of 8 individual MeOH-washed $\mathrm{Au}$ NCs based on (a-h) in situ AFM and (a'-h') SEM measurements. Cross-sectional line profiles were constructed from AFM topographies and SEM images (a"'-h'), then compared to visualize maximum height and width of CTAB ligands under hydrated and dehydrated conditions, respectively. (a) FWHM, determined in the line profile of AFM topography, (b) FWHM, determined in the line profile of SEM image. 
Table S7. CTAB ligand thickness quantification at the top surface of individual $\mathrm{MeOH}$-washed $\mathrm{Au}$ NCs in hydrated conditions, calculated from correlative analysis of in situ AFM and SEM in Figure S20 (unit: nm).

\begin{tabular}{ccccccccc}
\hline No. of Au NCs & $\# \mathbf{1}(\mathbf{a})$ & $\mathbf{\# 2}$ (b) & $\mathbf{\# 3}$ (c) & $\mathbf{\# 4}(\mathbf{d})$ & $\mathbf{\# 5}(\mathbf{e})$ & $\mathbf{\# 6}(\mathbf{f})$ & $\mathbf{\# 7}$ (g) & $\mathbf{\# 8}$ (h) \\
\hline $\begin{array}{c}\text { Max. height } \\
\text { (AFM) }\end{array}$ & 72.6 & 79.9 & 80.2 & 81.0 & 83.3 & 81.4 & 77.3 & 80.6 \\
$\begin{array}{c}\text { Edge length } \\
\text { (SEM) }\end{array}$ & 79.8 & 77.8 & 77.9 & 76.2 & 76.9 & 79.6 & 74.9 & 73.8 \\
\hline $\begin{array}{c}\text { CTAB } \\
\text { thickness at top } \\
\text { surface } \\
\text { in DI } \mathbf{H}_{2} \mathbf{O}\end{array}$ & -7.2 & 2.1 & 2.3 & 4.8 & 6.4 & 1.8 & 2.4 & 6.8 \\
\hline
\end{tabular}


Table S8. CTAB ligand thickness quantification at the sidewall of individual $\mathrm{MeOH}-$ washed $\mathrm{Au}$ NCs in hydrated and dehydrated conditions, calculated from correlative analysis of in situ AFM and SEM in Figure S20. CTAB layer thickness in hydrated condition was determined by FWHM measured by AFM (a) in Figure S20). The CTAB layer thickness in dehydrated condition was calculated from FWHM acquired from SEM image (b) in Figure S20) (unit: nm)

\begin{tabular}{|c|c|c|c|c|c|c|c|c|}
\hline $\begin{array}{l}\text { No. of } A u \\
\text { NCs }\end{array}$ & \#1 (a) & \#2 (b) & \#3 (c) & $\# 4$ (d) & \#5 (e) & \#6 (f) & \#7 (g) & Average \\
\hline $\begin{array}{l}\text { Edge length } \\
\text { (SEM) }\end{array}$ & 79.8 & 77.8 & 77.9 & 76.2 & 76.9 & 79.6 & 74.9 & $\begin{array}{l}77.6 \\
\pm 1.6\end{array}$ \\
\hline $\begin{array}{c}\text { FWHM } \\
\text { (a) in AFM) }\end{array}$ & 124.4 & 119.9 & 121.3 & 116.7 & 103.6 & 114.9 & 112.2 & $\begin{array}{l}116.1 \\
\pm 6.4\end{array}$ \\
\hline $\begin{array}{c}\text { CTAB } \\
\text { thickness in } \\
\text { hydrated } \\
\text { condition }\end{array}$ & 22.3 & 21.1 & 21.7 & 20.3 & 13.4 & 17.7 & 18.7 & $\begin{array}{r}19.3 \\
\pm 2.8\end{array}$ \\
\hline $\begin{array}{c}\text { FWHM } \\
\text { (b) in SEM) }\end{array}$ & 94.6 & 94.1 & 96.8 & 90.1 & 88.3 & 94.9 & 91.4 & $\begin{array}{l}92.9 \\
\pm 2.8\end{array}$ \\
\hline $\begin{array}{c}\text { CTAB } \\
\text { thickness in } \\
\text { dehydrated } \\
\text { condition }\end{array}$ & 1.8 & 2.6 & 3.9 & 1.3 & 0.1 & 2.1 & 2.7 & $\begin{array}{l}2.1 \\
\pm 1.1\end{array}$ \\
\hline
\end{tabular}




\section{In Situ AFM measurements of GC Substrates}

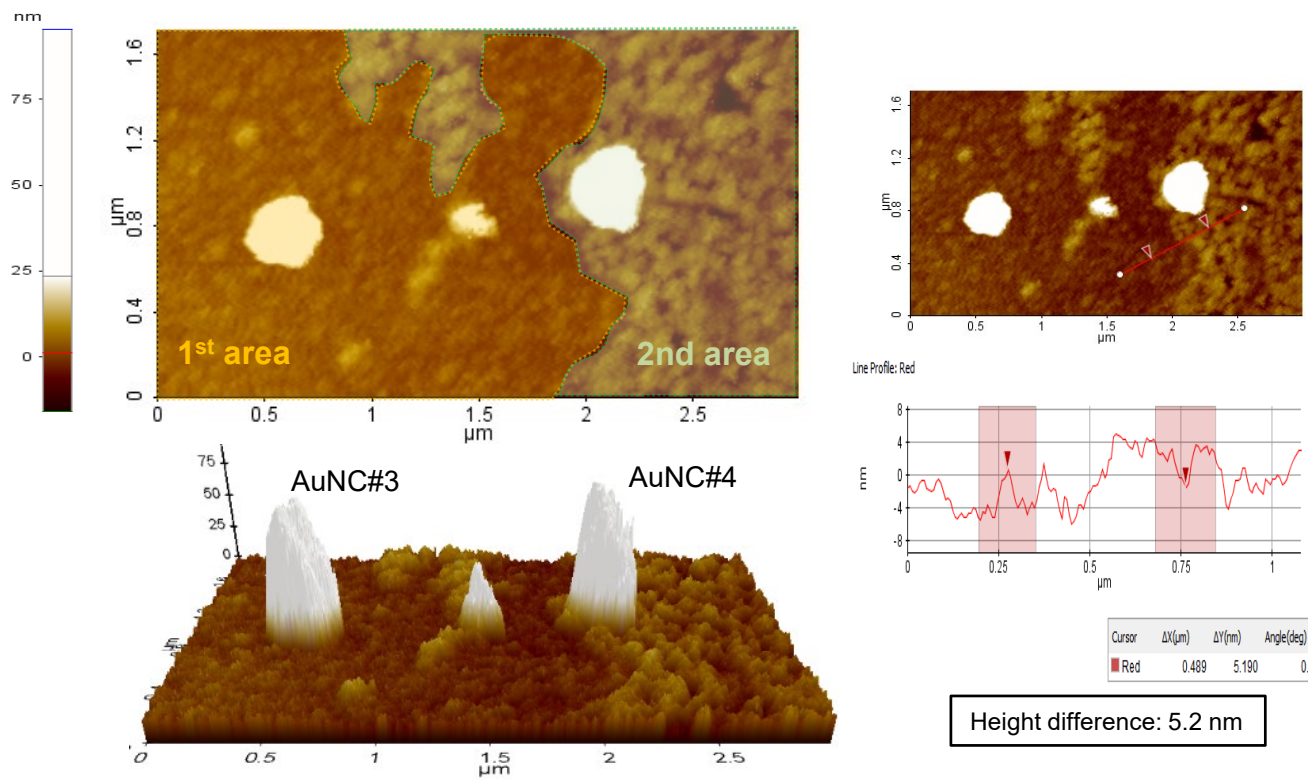

Figure S21. AFM topography of drop-cast $\mathrm{Au} \mathrm{NCs}$ under $\mathrm{H}_{2} \mathrm{O}$. On the background $\mathrm{GC}$ substrate, two layers of CTAB-coated area in different height were observed. The height difference between $1^{\text {st }}$ and $2^{\text {nd }}$ area was ca. $5.2 \mathrm{~nm}$. The $2^{\text {nd }}$ area with thicker CTAB layer might be attributed to aggregation of excessive amount of CTAB ligands. 

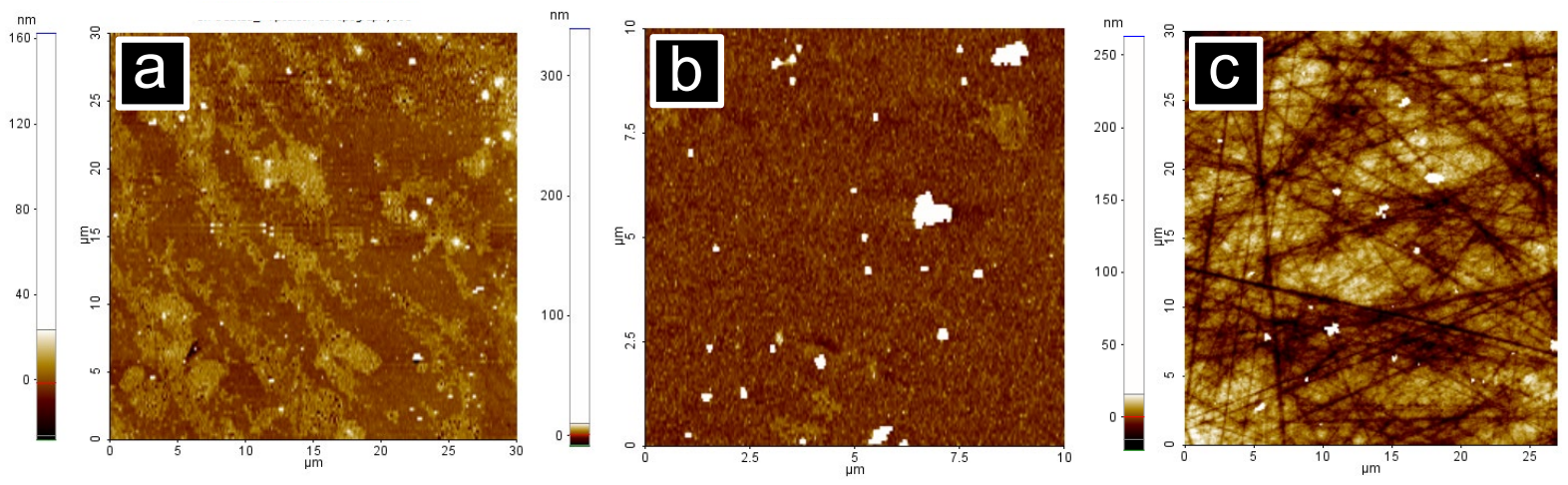

Figure S22. In situ AFM topographies of whole scanned area from (a) drop-cast, (b) $\mathrm{MeOH}-$ washed, and (c) EC-cleaned Au NCs. The observed CTAB residues on GC substrates were decreased over cleaning steps. EC-cleaning step finally revealed bare GC surface with scratches attributed to mechanical polishing by alumina. 

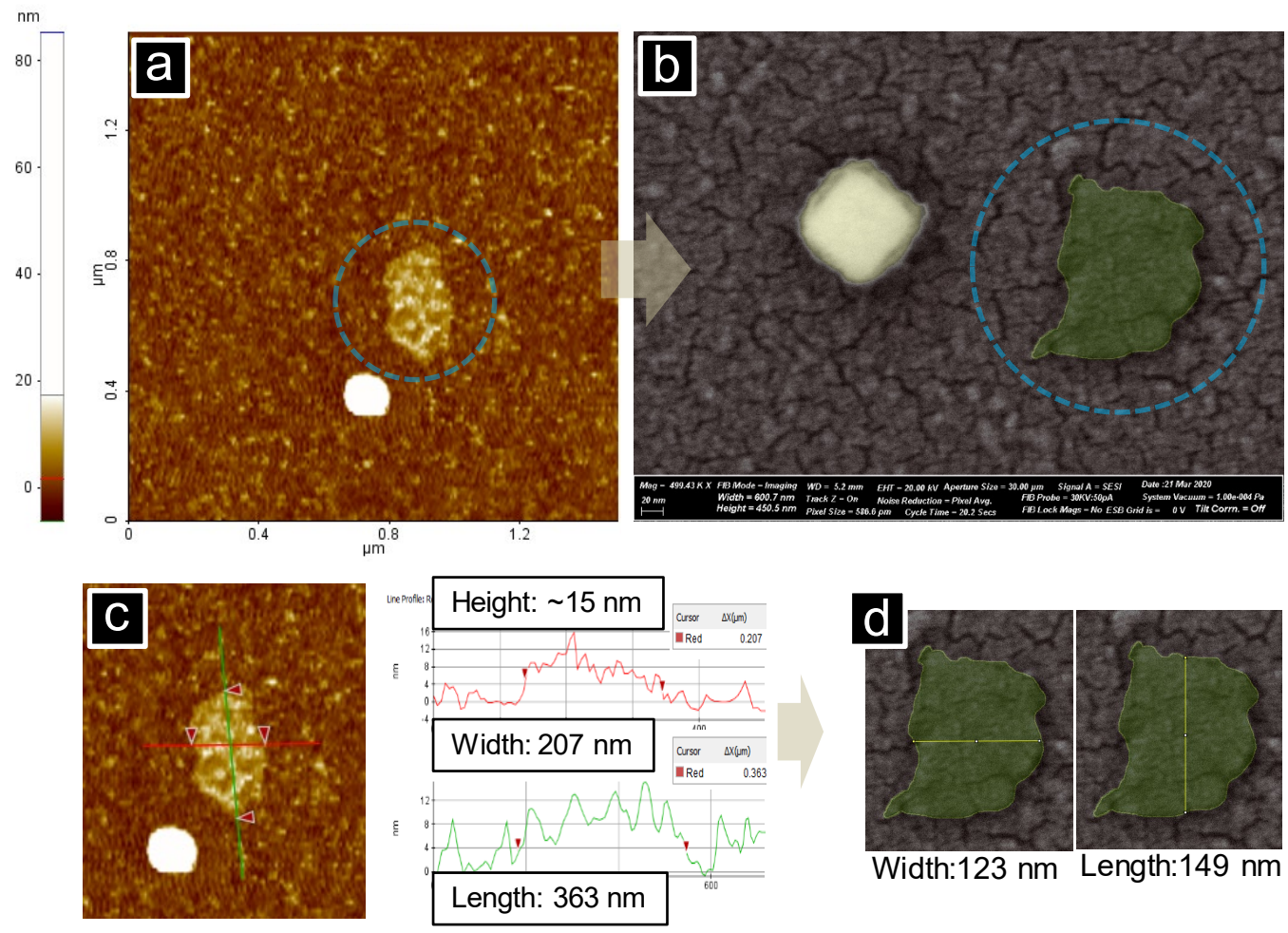

Figure S23. Measured dimension of CTAB residue on the GC substrate of MeOH-washed $\mathrm{Au}$ NCs by (a) in situ AFM and (b) SEM with ET detector. The width and length of CTAB residue recorded by AFM (c) was approximately twice greater than that measured by SEM (d). 


\section{REFERENCES}

1. O’Brien, M. N.; Jones, M. R.; Brown, K. A.; Mirkin, C. A., Universal Noble Metal Nanoparticle Seeds Realized Through Iterative Reductive Growth and Oxidative Dissolution Reactions. J. Am. Chem. Soc. 2014, 136, 7603-7606.

2. Nikoobakht, B.; El-Sayed, M. A., Preparation and Growth Mechanism of Gold Nanorods (NRs) Using Seed-Mediated Growth Method. Chem. Mater. 2003, 15, 1957-1962. 